\title{
Decalcification of cement mortars: Characterisation and modelling
}

\author{
I. Segura, M. Molero, S. Aparicio, J.J. Anaya, A. Moragues
}

\begin{abstract}
A B S T R A C T
This paper presents the results of a thorough microstructural characterisation of a set of cement mortars (made with three $\mathrm{w} / \mathrm{b}$ ratios and five different cement types), degraded by the ammonium nitrate method. Both destructive and ultrasonic non-destructive techniques were used to characterise the samples. The initial calcium content of the samples plays a dominant role in both the advance of the degradation process and the degradation grade of the samples. In addition, the decalcification process kinetics and the degradation grade are modelled, using Fick's second law of diffusion and the shrinking unreacted-core model. Two parametric equations are presented and used to estimate the decalcification process kinetics and the degradation grade using accessible microstructural parameters of the native mortars, such as the initial $\mathrm{CaO}$ content, the open porosity, and the cementitious matrix volume fraction. Furthermore, the degraded depth in the samples is measured using ultrasonic testing with an average error of about $10 \%$.
\end{abstract}

\section{Introduction}

Calcium leaching - decalcification - of cementitious materials is a degradation process caused by leaching of ions (mainly of calcium and hydroxide) from the pore solution of the cementitious matrix to the external environment. Decalcification can affect all the hydrated phases in the cement matrix depending on their solubilities. Portlandite will dissolve first as it has the highest solubility of all the hydrated phases. In accordance with solubility data provided by Berner [1,2], hydrated phases with higher $\mathrm{Ca} / \mathrm{Si}$ ratio will dissolve next. Subsequently we will find dissolution/precipitation fronts of the other hydrated phases. $\mathrm{C}-\mathrm{S}-\mathrm{H}$ gel undergoes a continuous decalcification process in which there is a progressive $\mathrm{C}-\mathrm{S}-\mathrm{H}$ dissolution, depending on $\mathrm{Ca} / \mathrm{Si}$ ratio. The overall decalcification process leads to the dissolution of hydrated phases from the cementitious matrix, thus increasing porosity and permeability and resulting in an overall loss of mechanical and durability properties [3-6]. A comprehensive description of the decalcification process can be found in Glasser et al. [7].

Several investigations have dealt with decalcification processes modelling, using different approaches to catch the coupled diffusion/dissolution phenomenon [8-12]. Furthermore, the coupled chemo-mechanical deterioration has been modelled [1317]. Kamali et al. [18,19] recently presented a simplified model predicting the one-dimensional leaching kinetics from a large experimental database of cement pastes. In addition to the significance of developing accurate models of these degradation processes, there is a consensus regarding the importance and need for the development of non-destructive techniques to both characterise and monitor cementitious materials. Ultrasonic testing has been used in several works to provide information about cementitious materials and their degradation processes [20-25], including decalcification processes [26-29].

This paper aims to provide a thorough microstructural characterisation of a set of cement mortars, to relate the microstructural characteristics of the samples to the progression and extent of the decalcification process. Five cement types and three w/b ratios were used to make the mortar samples. The microstructural characterisation was performed using several destructive techniques (DTA/TG, XRD, MIP, open porosity measurements and leachate analysis) and using non-destructive ultrasonic measurements. The decalcification process kinetics and the degradation grade are modelled using two parametric equations, defined with microstructural parameters of the native material. Eventually, degraded depths are estimated using the proposed equations and ultrasonic measurements. Finally, comparisons between estimated and measured results are discussed. 
Table 1

Mix design of the mortars used in this work.

\begin{tabular}{llll}
\hline Component $(\mathrm{g})$ & Sample & & MC6030 \\
\cline { 2 - 4 } & MC4030 & MC5030 & M50 \\
\hline Cement & 450 & 450 & 1350 \\
Sand & 1350 & 1350 & 270 \\
Water & 180 & 225 & 0.6 \\
w/b Ratio & 0.4 & 0.5 & $3 / 1$ \\
s/b Ratio & $3 / 1$ & $3 / 1$ & \\
\hline
\end{tabular}

\section{Experimental}

\subsection{Materials}

Five cement types with different type and content of additions (limestone filler, low-calcium type fly-ash and blast-furnace slag) were used to fabricate the prismatic mortar bars (dimensions of $40 \times 40 \times 160 \mathrm{~mm}$; see Tables 1 and 2); considering the mix dosage and the chemical composition of the cements, the initial $\mathrm{CaO}$ concentration, $\mathrm{CaO}_{c}$, and the $\mathrm{CaO} / \mathrm{SiO}_{2}$ molar ratio of the samples were calculated. All cements are commercial cements, with their ranges of additions' content specified by Spanish standards [30]: 6-20\% for CEM II/A-V $42.5 \mathrm{R}, 21-35 \%$ for CEM II/B-M (V-L) 32.5 $\mathrm{N}, 66-80 \%$ for CEM III/B 32.5N-SR-BC and 36-55\% for CEM IV/B (V) $32.5 \mathrm{~N}$. Natural rounded sand rich in quartz, supplied by Eduardo Torroja Institute for Construction Science (CEN-Standard Sand EN 196) was also used. Mortar bars were stored in their moulds in a climate chamber for $24 \mathrm{~h}\left(96 \% \mathrm{RH} / 20^{\circ} \mathrm{C}\right)$ and after demoulding they were cured under lime-saturated water at $20^{\circ} \mathrm{C}$ for 28 days. They were then cut into cubic pieces ( $40 \mathrm{~mm}$ side) using a diamond saw cooled with water.

\subsection{Accelerated decalcification experiment}

Accelerated decalcification was achieved by immersing the samples in concentrated ammonium nitrate solution $(460 \mathrm{~g} / \mathrm{L})$ for 32 days, with a solution-to-sample volume ratio of 11 . Such factors (solution concentration and solution-to-sample volume ratio) ensure the aggressiveness of the solution throughout the experiment, thus avoiding the renewal of the solution. The acceleration of the decalcification process using ammonium nitrate has been used by several authors $[3,13,14,31-34]$. This method accelerates the decalcification process by approximately 150 times as compared with the same process in deionised water, but diffusion remains the rate controlling factor [3]; a detailed description of the characteristics of the method can be found in the works of Carde et al. $[35,36]$ and Heukamp $[3,37]$. Each aggressive solution was prepared $48 \mathrm{~h}$ ahead of the experiment to ensure its homogeneity. During the experiment, each solution container was continuously stirred to avoid ion concentration near the samples' surface.

Two parallel faces of each cubic sample were sealed with epoxy resin (Sikaguard 62), to prevent corner effects and to avoid a three-dimensional degradation process. In addition, to avoid capillary suction phenomena, the samples were immersed for $48 \mathrm{~h}$ in deionised water. For each degradation time, two cubic samples were immersed in the aggressive media. The samples were taken out of the solutions after $4,11,21$ and 32 days. Immediately after their extraction from the aggressive solutions the samples were immersed in deionised water for $72 \mathrm{~h}$ to avoid the formation of expansive $3 \mathrm{CaO} \cdot \mathrm{Al}_{2} \mathrm{O}_{3} \cdot \mathrm{Ca}\left(\mathrm{NO}_{3}\right)_{2} \cdot 10 \mathrm{H}_{2} \mathrm{O}$ [36]. Further information about the procedure followed here can be found in [38].

\subsection{Microstructural characterisation}

\subsubsection{Cementitious matrix characterisation}

Cementitious matrix was characterised only in the samples of $\mathrm{w} / \mathrm{b}$ ratio 0.5 , by X-ray diffraction (XRD) and thermal analyses (DTA/TG). Crystalline phase determination was made by XRD analyses in a BrukerD8 Advance Powder Diffractometer (5-65 $2 \theta$; $0.033^{\circ} 2 \theta / s$ ). Powdered samples for the XRD and DTA/TG measurements were obtained by milling $10 \mathrm{~mm}$-thick slices in an agate mortar grinder until it passed through the $0.16 \mathrm{~mm}$ sieve. Thermal analyses were made to quantify both the portlandite and calcite content in the samples. The samples were analysed in a Stanton Redcroft STA-781 $\left(20-1.100{ }^{\circ} \mathrm{C} ; 10^{\circ} \mathrm{C} / \mathrm{min}\right.$; $\mathrm{N}_{2}$ flux: $\left.80 \mathrm{~mL} / \mathrm{min}\right)$.

To relate portlandite and calcite contents to the content of cementitious matrix, the endothermic peak observed in the DTA during cooling at $570{ }^{\circ} \mathrm{C}$ (due to the conversion of $\beta$-quartz to $\alpha$ quartz) was used. A calibration curve for $\mathrm{SiO}_{2}$ can be constructed since the peak area of the DTA curve is dependent on the sample mass [39], assuming that quartz is inert during the decalcification process $[40,41]$ and remains constant before and after degradation, Several DTA analyses were made with increasing quantities of the same sand used to fabricate the samples, and a calibrate curve was obtained. Therefore relative contents $\left(S_{i}\right.$ expressed in terms of percent of compound in the cementitious matrix) of both portlandite and calcite could be used using the following equation:

$S_{i}(\%)=\frac{100 \cdot s_{i} \cdot M_{i}}{\left(m_{i}-\left(60.08 \cdot\left(\frac{A_{570^{\circ}-a}}{b}\right)\right)\right)}$

where $s_{i}$ is the compound content as determined from DTA/TG analysis ( $\mathrm{mol}$ ), $M_{i}$ is the molecular weight of each compound $(\mathrm{g} / \mathrm{mol}), m_{i}$ the sample weight used in the analysis $(\mathrm{g}), A_{570^{\circ}}$ the area of the peak at $570{ }^{\circ} \mathrm{C}$ and both $a$ and $b$ are the parameters of the calibration curve $\left(a=37.07, b=56.59 \mathrm{~mol}^{-1}\right)$.

\subsubsection{Degraded depth profiles}

Degraded depths in the mortar samples were revealed using the standard phenolphthalein test for carbonation [31,42]. Degraded and native samples were cut parallel to the sealed faces and sprayed with the phenolphthalein solution, and a set of images of the stained surfaces were obtained with a digital camera (Olympus C-765; image resolution: $3200 \times 2400$ pixels, with a colour depth of 24 bits). The degraded depth was determined by an automatic digital image processing algorithm, providing automatic,

Table 2

Composition of the five cements used.

\begin{tabular}{|c|c|c|c|c|c|c|c|c|c|c|c|c|c|}
\hline \multirow[t]{2}{*}{ Cement type } & \multirow[t]{2}{*}{ Type of addition $^{\mathrm{a}}$} & \multicolumn{8}{|c|}{ Chemical composition (\%) } & \multirow[t]{2}{*}{$\mathrm{C} / \mathrm{S}$} & \multirow[t]{2}{*}{$\mathrm{CaO}_{c}(\mathrm{~mol})$} & \multirow[t]{2}{*}{ Blaine $\left(\mathrm{cm}^{2} / \mathrm{g}\right)$} & \multirow[t]{2}{*}{ Density $\left(\mathrm{g} / \mathrm{cm}^{3}\right)$} \\
\hline & & $\mathrm{CaO}$ & $\mathrm{SiO}_{2}$ & $\mathrm{Al}_{2} \mathrm{O}_{3}$ & $\mathrm{Fe}_{2} \mathrm{O}_{3}$ & $\mathrm{MgO}$ & $\mathrm{K}_{2} \mathrm{O}$ & $\mathrm{Na}_{2} \mathrm{O}$ & $\mathrm{SO}_{3}$ & & & & \\
\hline CEM I 42.5 R-SR & $\mathrm{LF}$ & 65.16 & 20.85 & 4.4 & 4.83 & 1.73 & 0.92 & 0.63 & 1.35 & 3.46 & 5.2 & 4265 & 3.16 \\
\hline CEM II/A-V 42.5 R & $\mathrm{FA}+\mathrm{LF}$ & 53.8 & 23.2 & 8.18 & 4.68 & 1.89 & 1.48 & 0.12 & 2.76 & 2.24 & 4.46 & 3210 & 3.01 \\
\hline CEM II/B-M (V-L) $32.5 \mathrm{~N}$ & $\mathrm{FA}+\mathrm{LF}$ & 52.14 & 24.41 & 8.81 & 3.22 & 2.66 & 0.38 & 1.19 & 2.6 & 2.07 & 4.13 & 3120 & 2.94 \\
\hline CEM III/B 32.5 N-SR-BC & BFS & 45.7 & 27.7 & 12.5 & 0.98 & 7.3 & 0.5 & 0.2 & 2.4 & 1.76 & 3.67 & 4950 & 2.95 \\
\hline CEM IV/B (V) $32.5 \mathrm{~N}$ & $\mathrm{FA}+\mathrm{LF}$ & 43.44 & 28.1 & 12.05 & 5.37 & 1.8 & 1.61 & 0.14 & 2.4 & 1.35 & 3.42 & 3440 & 2.87 \\
\hline
\end{tabular}

${ }^{a}$ LF: limestone filler; FA: fly ash, low-calcium type; BFS: blast-furnace slag. 
repetitive, reproducible and precise measurements (the precision of the automatic image processing procedure is about $0.03 \mathrm{~mm}$ ). The degraded depths were measured on each one of the four sides of the samples and the average values of the degraded depth, $\hat{e}_{D}$, were obtained from those values (approximately 900 measurements in each side). Further information about the procedure can be found in $[38,43]$. Throughout this paper the decalcification front will be defined as a sharp decalcification front delimited from the sound core by total dissolution of portlandite, in accordance with other published works $[8,9,44]$. Although it is well established that cement paste degradation may begin at $\mathrm{pH}$ values above that of portlandite equilibrium (12.5), several authors regard the coloured zone obtained after phenolphthalein spraying as the sound zone $[31,33,45]$. Previous results obtained by the authors support this statement by comparing degraded depths obtained by the phenolphthalein test with those obtained from SEM/EDX analyses [29].

\subsubsection{Porous microstructure characterisation}

Porous microstructure of the samples was characterised by measuring their open porosity and using mercury intrusion porosimetry (MIP) measurements. The open porosity of native and degraded samples was obtained from the RILEM water absorption method [46] but for two minor modifications: the procedure duration was reduced ( $3 \mathrm{~h}$ in each step, instead of $24 \mathrm{~h}$ [47]) and the drying temperature was diminished $\left(80^{\circ} \mathrm{C}\right.$ instead of $\left.105^{\circ} \mathrm{C}\right)$ and relegated to the last step. Apparent and bulk densities, and thus the open porosity of the samples, can be obtained by just applying the Archimedes method.

MIP analyses were made only in the samples of $\mathrm{w} / \mathrm{b}$ ratio 0.5 . A Micromeritics Autopore IV 9500 porosimeter was used for the measurements (from 0.007 to $230 \mathrm{MPa}$; three measurement per sample). Samples for these measurements were obtained by cutting a $20 \mathrm{~mm}$-thick slice from the cubic samples; from these slices, cylindrical samples (10 $\mathrm{mm}$ diameter) were cored using a round column drill equipped with a diamond drill bit cooled with water. The samples were drawn from the outer part of the slice, to include as much degraded zone as possible for analysis. They were first oven-dried at $40{ }^{\circ} \mathrm{C}$ for 4 days and subsequently vacuum-dried at $7 \times 10^{-6} \mathrm{MPa}$ for $15 \mathrm{~min}$. A cylindrical pore-shape model was used to apply the well-known Washburn equation $(\gamma=485 \mathrm{mN} / \mathrm{m}$ and $\theta=130^{\circ}$ ) and to obtain pore diameters from MIP results. The total porous area, $A_{p}$, was calculated from the reversible work done during mercury intrusion [48].

\subsubsection{Aggressive solution characterisation}

The $\mathrm{pH}$ of the aggressive solutions was measured continuously for the first 4 days of the degradation process; thereafter, it was measured daily until the end of the experiment. To monitor the $\mathrm{Ca}^{2+}$ content in the aggressive solutions, two aliquots $(10 \mathrm{~mL})$ were extracted per day. The $\mathrm{Ca}^{2+}$ content in the aliquots was measured by an automatic titrator, using EDTA solution as titration agent and both Eriochrome Black $\mathrm{T}$ and photometric identification of the titration end-point. Triethanolamine was used to mask $\mathrm{Fe}^{3+}$ and $\mathrm{Al}^{3+}$ when in solution; Complexon-Magnesium solution $(0.1 \mathrm{M})$ was added to the titration to ensure a good colour-turn at the end-point of the titration.

\subsubsection{Non-destructive ultrasonic characterisation}

Non-destructive characterisation was carried out by measuring the ultrasonic velocity of the specimens. Instead of using the usual direct or indirect transmission measurements by the contact method and with commercial equipment, a more precise method was used. Such method entails water immersion measurements, high frequency transducers and digital signal processing. The longitudinal ultrasonic velocity of the samples $(V)$ was calculated using the following equation:
$V=\frac{e}{t_{c}-t_{w}+e / V_{w}}$

where $e$ represents the path length of the specimen, $t_{c}$ is the travelling time of the signal through the specimen, $t_{w}$ is the travelling time in water (with the specimen absent) and $V_{w}$ is the ultrasonic velocity in water; an aluminium standard probe was used in all the ultrasonic inspections to determine $V_{w}$ in a precise way, since it is highly influenced by water's temperature. Two pulse-echo inspections (one by each side of the samples) were made to precisely determine the path length at each point of the samples (about $0.1 \mathrm{~mm}$ precision), using the travelling time measurement of the interface echo, thereby obtaining precise ultrasonic velocity measurements. After obtaining the ultrasonic velocity maps, the central zone of the samples was used to obtain average ultrasonic velocities $\left(\widehat{V}_{t}\right)$ to avoid edge effects (as interferences can be found in those areas), and allow qualitative analyses of the ultrasonic velocity variation. The average ultrasonic velocities are latter obtained from a central area of $30 \times 10 \mathrm{~mm}$ for each degraded and non degraded specimen, yielding averages of 300 individual ultrasonic signals. Further details on the ultrasonic technique are given in $[25,29]$.

\section{Results of the microstructural characterisation of the samples}

\subsection{Cementitious matrix characterisation}

The degradation process has a marked effect on the microstructure of the cementitious matrix, as can be seen in the XRD patterns (Fig. 1). The results obtained are in accordance with the bibliography; in all the samples, the intensity of the portlandite peak intensity decreases as the decalcification progresses. The differences in portlandite content of the native samples, obtained from thermal analyses, are indeed large (Fig. 2a) conditioning the behaviour of the samples during the decalcification process. The portlandite content of the native samples, $S_{\mathrm{CH}, 0}$, is related to the initial calcium content of the samples, as can be seen in Fig. $2 \mathrm{~b}$.

The decalcification process is mainly a neutralisation process, in which the $\mathrm{OH}^{-}$ions of the aqueous pore phase are neutralised by the $\mathrm{H}_{3} \mathrm{O}^{+}$ions of the aggressive solution. This neutralisation process promotes $\mathrm{Ca}^{2+}$ diffusion from the material and dissolution of the hydrated cementitious phases (portlandite, ettringite, AFm phases, and $\mathrm{C}-\mathrm{S}-\mathrm{H}$ gel). Portlandite is one of the most important hydration products controlling the neutralisation capacity of cementitious materials. The samples with higher portlandite contents will exhibit, at least in the initial stages, greater neutralisation capacity. Thus, the decalcification process will be slowed during its initial stages in those samples. However, higher portlandite contents in the native samples will result in larger porosity increase.

\subsection{Degraded depth measurement}

The typical sound core/peripheral decalcified zone was observed after spraying the samples with phenolphthalein solution (Fig. 3). The $\hat{e}_{D}$ obtained vary depending on the cement type and the $\mathrm{w} / \mathrm{b}$ ratio (Fig. 4). As $\mathrm{w} / \mathrm{b}$ ratio increases, samples with lower initial calcium contents (i.e.: CEM II/B, CEM III and CEM IV) exhibit higher degraded depths during the initial stages of the degradation process. As shown in Fig. 2b, portlandite content in the native samples is related to their initial calcium content. Thereby, samples with lower initial calcium content (i.e.: CEM II/B, III and IV) may exhibit lower neutralisation capacity $[40,49,50]$ and thus larger degraded depths in the initial stages of the decalcification process. It is worth noting that larger degraded depths do not necessarily indicate higher degradation grade. Although the degradation front 

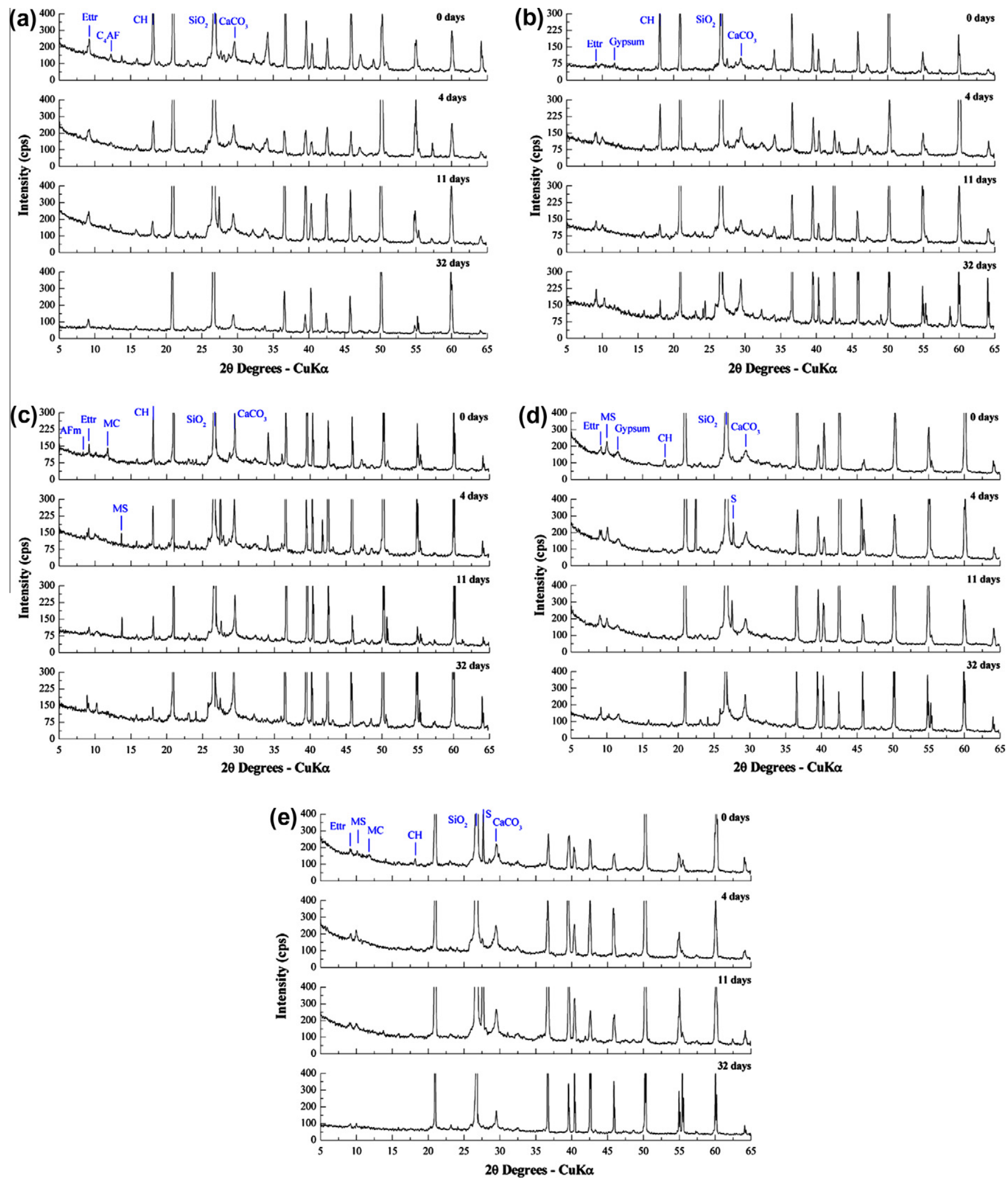

Fig. 1. Variations in the XRD patterns with the degradation time - w/b ratio 0.5: (a) CEM I, (b) CEM II/A, (c) CEM II/B, (d) CEM III, and (e) CEM IV.

can advance further inward into the samples with lower initial calcium contents, total calcium content dissolved will be presumably lower [50]. As the degradation process advances and portlandite dissolves, other hydrated products of the cementitious matrix (ettringite, $\mathrm{C}-\mathrm{S}-\mathrm{H}$ gel) will contribute to the neutralisation capacity of the samples [49]. 

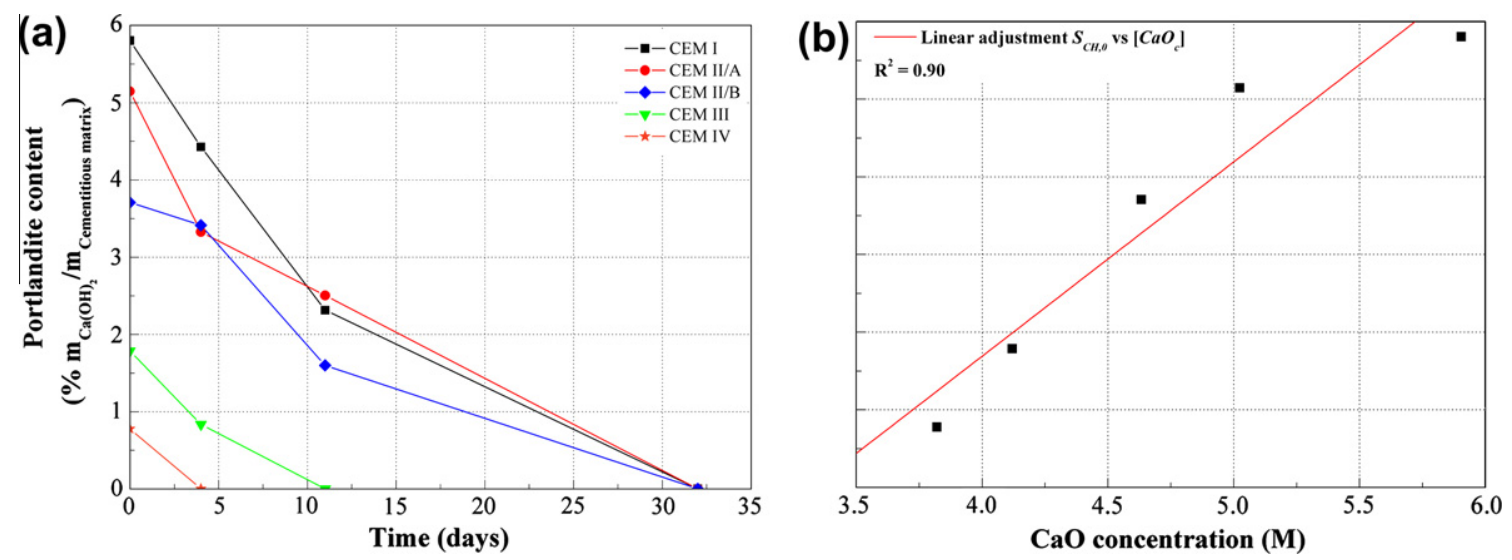

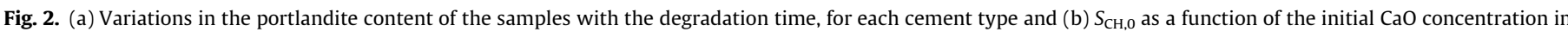
the native samples $-\mathrm{w} / \mathrm{b}$ ratio 0.5 .

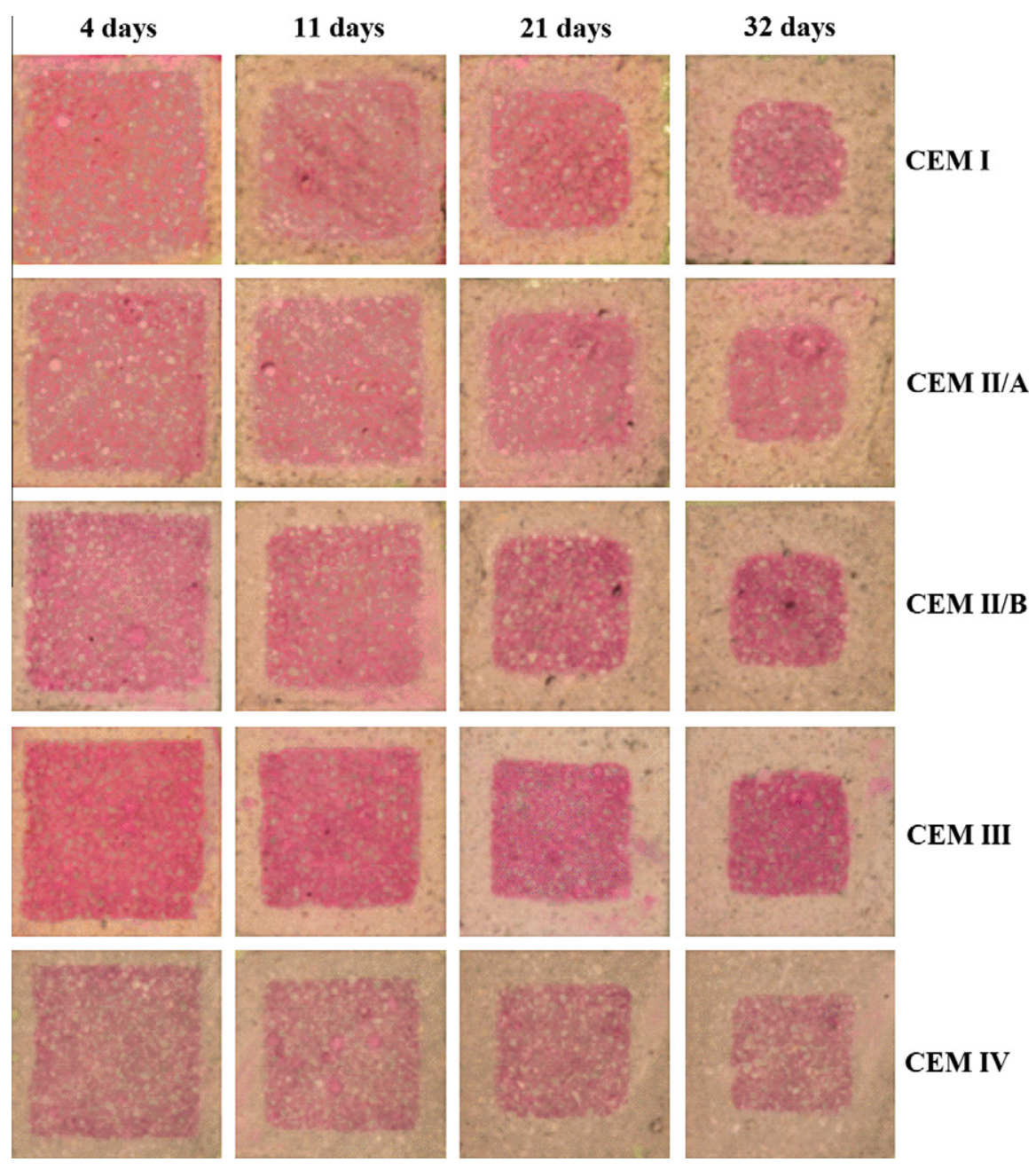

Fig. 3. Images of the degraded samples' surfaces, obtained after spraying them with phenolphthalein solution.

\subsection{Porous microstructure characterisation}

The open water porosity of the native samples was characterised in all the cubic samples (12 measurements; average values are shown in Table 3). Since both cement type and w/b ratio influences the porosity of the native samples, relative increments will be analysed instead of absolute values. The relative porosity increase $\Delta \phi_{r}$ (\%) can be obtained using Eq. (3), to analyse its variation with the degradation time (see Fig. 5):

$\Delta \phi_{r}(\%)=\frac{\phi_{t}-\phi_{0}}{\phi_{0}} \cdot 100$

where $\phi_{t}$ is the porosity at each degradation time and $\phi_{0}$ the open porosity of the native material. For all the w/b ratios, the samples 

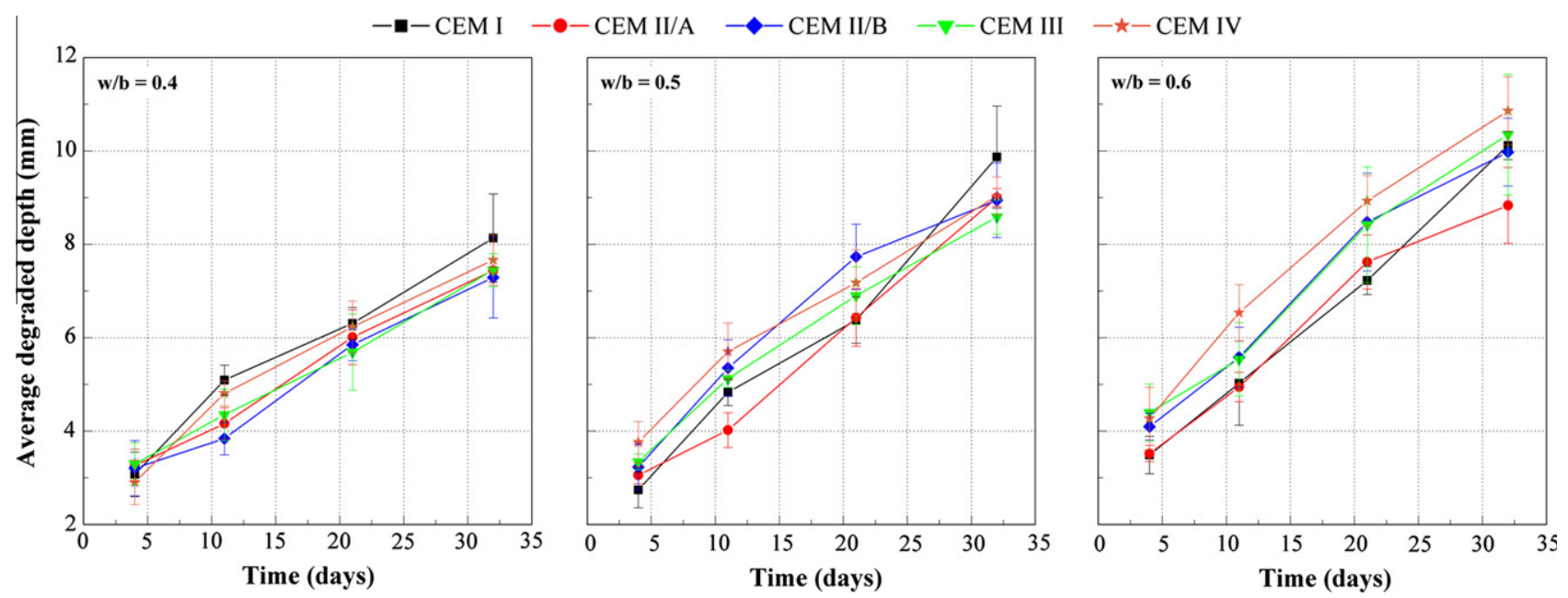

Fig. 4. Variations in the average degraded depths with degradation time, for each cement type and w/b ratio.

Table 3

Average open water porosities of the native samples, for each cement type and $\mathrm{w} / \mathrm{b}$ ratio.

\begin{tabular}{llll}
\hline Cement type & \multicolumn{2}{l}{$\begin{array}{l}\text { Open water porosity (\%) } \\
\text { w/b ratio }\end{array}$} \\
\cline { 2 - 4 } & 0.4 & 0.5 & 0.6 \\
\hline CEM I & $14.7 \pm 0.1$ & $17.5 \pm 0.2$ & $20.0 \pm 0.2$ \\
CEM II/A & $15.1 \pm 0.1$ & $17.7 \pm 0.1$ & $19.8 \pm 0.4$ \\
CEM II/B & $14.9 \pm 0.1$ & $17.8 \pm 0.2$ & $19.4 \pm 0.2$ \\
CEM III & $14.2 \pm 0.2$ & $18.0 \pm 0.1$ & $20.5 \pm 0.1$ \\
CEM IV & $13.8 \pm 0.1$ & $16.7 \pm 0.1$ & $21.0 \pm 0.4$ \\
\hline
\end{tabular}

from CEM I exhibit the larger $\Delta \phi_{r}$ values, pointing out high degradation grade of those samples. In addition, samples from CEM III and CEM IV show precipitation phenomenon, in the form of negative values for $\Delta \phi_{r}$, after 11 and 4 days of degradation, respectively. Such phenomenon has been described before [50-52], although no evidence can be found for such decreases in the open water porosity. Almost all samples exhibit decreases of $\Delta \phi_{r}$ when the w/b ratio increases in accordance to the references [6,52,53].

The increase of pore volume during decalcification is mainly attributed in the literature to the dissolution of portlandite. Haga et al. [4], related the portlandite content variation to the porosity increase and thus ascertain if the porosity increase is mainly related to portlandite dissolution. In this paper the pore volume resulting from the dissolution of portlandite, $\phi_{\mathrm{CH}}$ ( $\mathrm{pp}$, percentage points), has been calculated using a modified version of the formula proposed by Haga et al.:

$\phi_{\mathrm{CH}}(\mathrm{pp})=M_{\mathrm{CH}}^{v} \cdot\left[\left(\frac{\rho_{m, 0} \cdot S_{\mathrm{CH}, 0}}{M_{\mathrm{CH}}}\right)-\left(\frac{\rho_{m, t} \cdot S_{\mathrm{CH}, t}}{M_{\mathrm{CH}}}\right)\right]$

where $\rho_{m, 0}$ is the bulk density of the cementitious matrix $\left(\mathrm{g} / \mathrm{cm}^{3}\right)$, and $S_{\mathrm{CH}, 0}$ the portlandite content (expressed as the portlandite-tocementitious matrix mass ratio) in the native samples; $\rho_{m, t}$ is the bulk density of the cementitious matrix $\left(\mathrm{g} / \mathrm{cm}^{3}\right)$ and $S_{\mathrm{CH}, t}$ the portlandite content (expressed as the portlandite-to-cementitious matrix mass ratio) in each degraded sample; $M_{\mathrm{CH}}$ is the molecular weight of portlandite $(74 \mathrm{~g} / \mathrm{mol})$ and $M_{\mathrm{CH}}^{v}$ ) the molecular volume of the portlandite $\left(33 \mathrm{~cm}^{3} / \mathrm{mol}\right)$, calculated from its density. $\rho_{m}$ is estimated considering the sample dosage and the bulk density measured by the RILEM method $\left(\rho_{r}\right)$, as:

$\rho_{r}=\rho_{\text {agg }} \cdot \underbrace{\left(\frac{\zeta_{\text {agg }}}{\zeta_{\text {agg }}+\zeta_{m}}\right)}_{\zeta_{\text {agg }}^{S}}+\rho_{m} \cdot \underbrace{\left(\frac{\zeta_{m}}{\zeta_{\text {agg }}+\zeta_{m}}\right)}_{\zeta_{m}^{S}}$
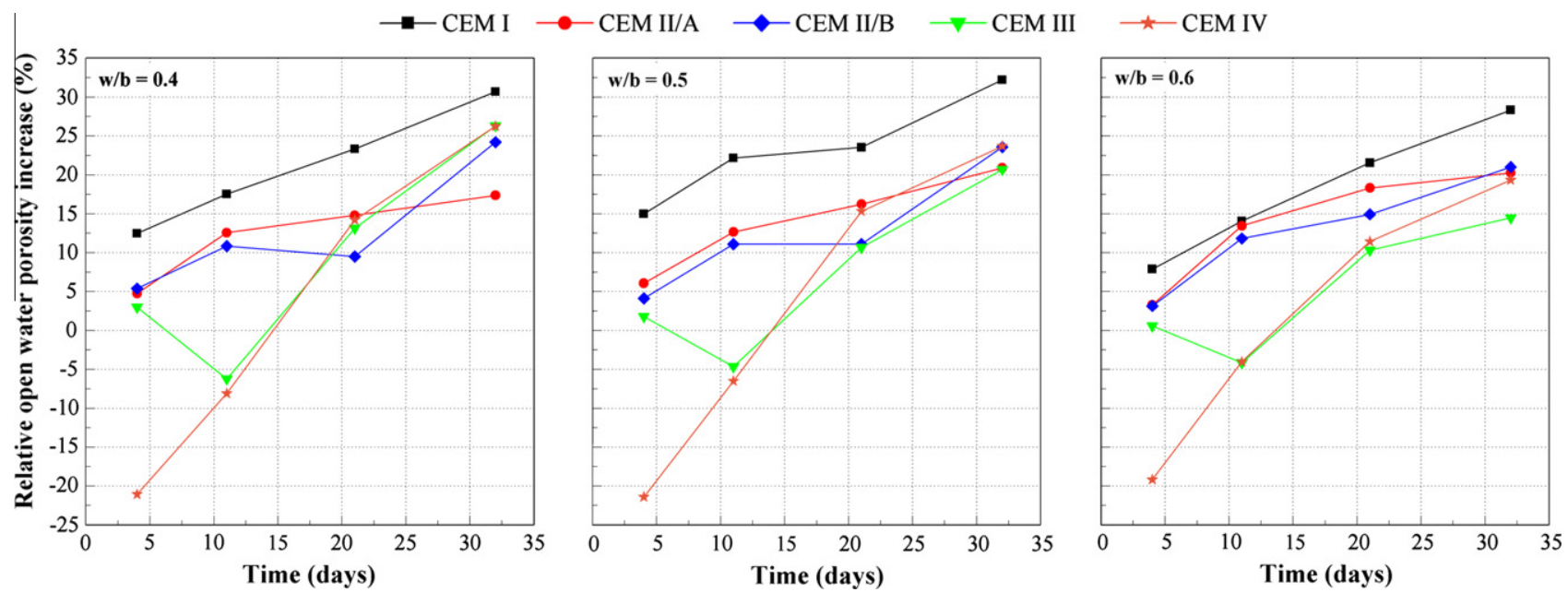

Fig. 5. Variations in $\Delta \phi_{r}$ with the degradation time, for each cement type and w/b ratio. 
Table 4

Comparisons of $\Delta \phi_{\mathrm{CH}}$ calculated values with $\Delta \phi$ measured values, w/b ratio 0.5 .

\begin{tabular}{lcll}
\hline Cement type & Time (days) & $\phi_{\mathrm{CH}}(\mathrm{pp})$ & $\Delta \phi(\mathrm{pp})$ \\
\hline CEM I & 4 & 1.32 & 2.62 \\
& 11 & 3.33 & 3.89 \\
CEM II/A & 32 & 5.31 & 5.64 \\
& 4 & 2.01 & 1.08 \\
& 11 & 2.72 & 2.24 \\
CEM II/B & 32 & 4.85 & 3.70 \\
& 4 & 0.58 & 0.73 \\
CEM III & 11 & 2.28 & 1.98 \\
CEM IV & 32 & 3.82 & 4.20 \\
& 32 & 1.55 & 3.73 \\
\end{tabular}

An expression for $\rho_{m}$ is then obtained as:

$\rho_{m}=\frac{\left(\rho_{r}-\left(\rho_{\text {agg }} \cdot \zeta_{\text {agg }}^{S}\right)\right)}{\zeta_{m}^{S}}$

Thus, $\phi_{\mathrm{CH}}$ values can be calculated with Eq. (4) and compared with the absolute porosity increases, $\Delta \phi(\mathrm{pp})$ as measured by the open water porosity (see Table 4 ). Whenever $\Delta \phi$ is higher than $\phi_{\mathrm{CH}}$ there is dissolution of other hydrated phases than portlandite from the cementitious matrix. It is worth noting that samples with grossly different $S_{\mathrm{CH}, 0}$ contents (as those of cement types CEM II/A, II/B, III and IV), show very similar values of $\Delta \phi$. The larger values of $\Delta \phi$ for the samples of CEM III and CEM IV could be caused by the dissolution of both non-reacted blast-furnace slag and fly ash, although further data are needed to clarify this question.

The pore size distributions of the different degraded samples (Fig. 6) show similar trends. The samples with higher initial calcium contents (cement types CEM I and II/A) exhibit greater variations by the decalcification process in their porous microstructure. Almost all the pore size distributions have their maximum pore volume close to $0.07 \mu \mathrm{m}$. This maximum is called "critical pore diameter", $d_{c}$, related to the pressure at which a percolation path forms in the porous network of the material [54]. Values close to this diameter suggest the possible existence of a common percolation path related to clinker hydration in those cements. As the pozzolanic reactions increase, the size of $d_{c}$ changes and so does the pore size distribution (Fig. 7a). The large increase in the value of $d_{c}$ of the samples of CEM II/B after 32 days of degradation is caused by the appearance of a new peak in the pore size distribution because of the progress of the degradation process, as seen in Fig. 6c. The variation of the "threshold diameter", $d_{t}$, related to the pore size at which porous network percolation starts [55,56], as well as the variation on the total porous area, $A_{p}$, (see Fig. 7b and $\mathrm{c}$, respectively) reveal the high degradation grade of the samples of CEM I. In the samples of CEM IV, variations in $d_{t}$ and $A_{p}$ are negligible during the degradation process, except for the increase in the initial days of the degradation process. The samples made from other cement types show similar increases in $A_{p}$.

\subsection{Aggressive solutions characterisation}

As can be seen in Fig. 8, cement type plays the major role in the variation of the calcium content in solution with degradation time. Except for the samples of CEM III, leached calcium increases as the initial calcium content of the samples increases. Calcium content in solution is weighted by the initial calcium content of each sample (Fig. 9), to provide a better measurement of how severe is the dissolution of the hydrated compounds and hence the degradation grade of the cementitious matrix. The cementitious matrices in the samples from CEM I, CEM II/A and CEM II/B have been leached the same extent, with a percentage of calcium leached ranging from $1.4 \%$ to $1.6 \%$. Samples from CEM III exhibit the lesser degradation grade, with a content of calcium leached between $1 \%$ and $1.25 \%$. As the $\mathrm{w} / \mathrm{b}$ ratio increases, the differences in calcium leached between the samples from CEM IV and CEM III are lowered, as more calcium is leached from the last ones. Therefore, the lower is the initial calcium content in the sample, the lower
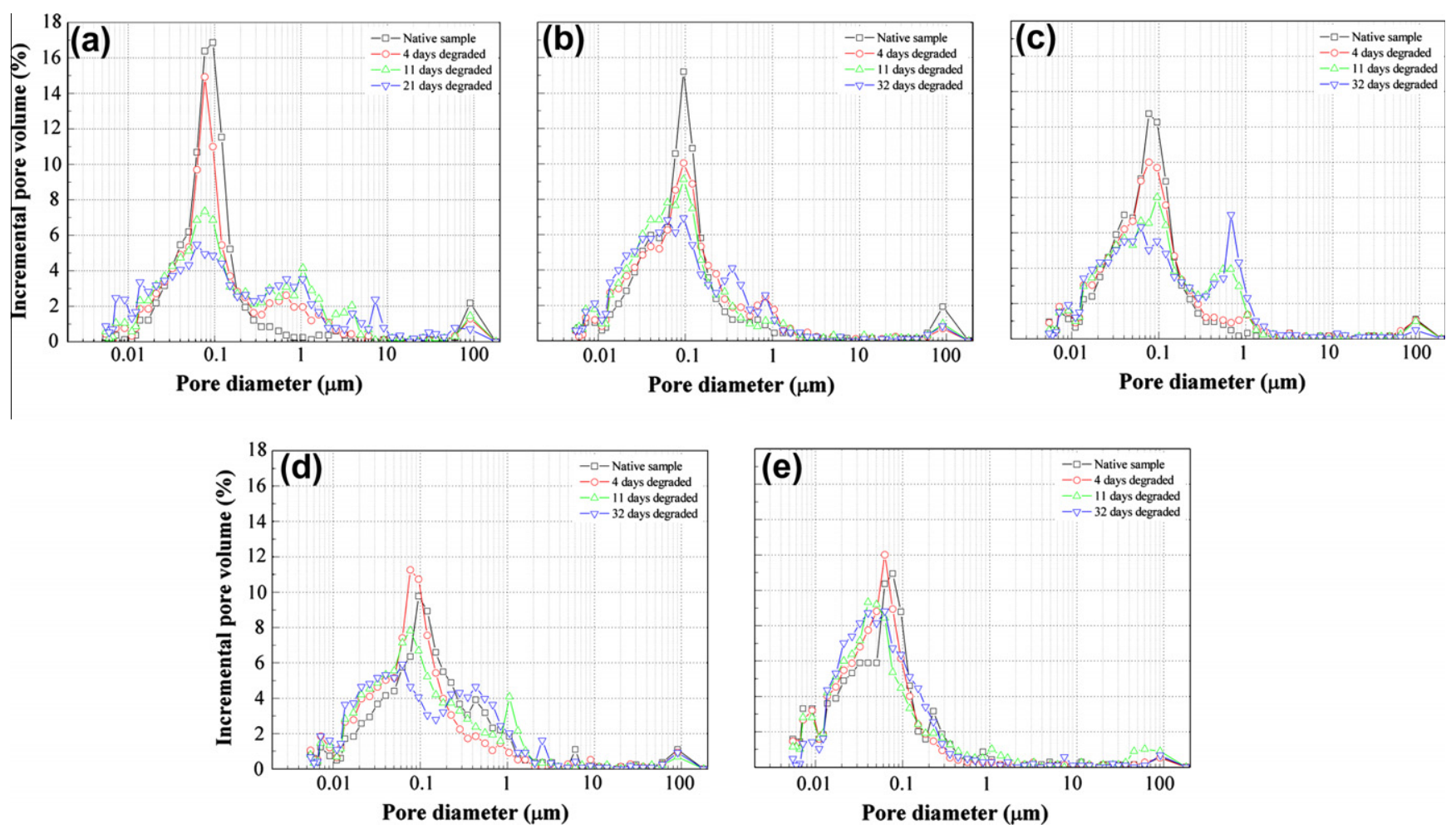

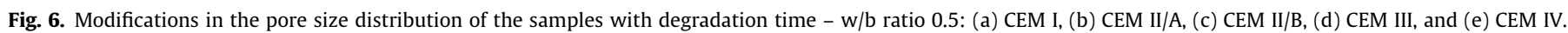



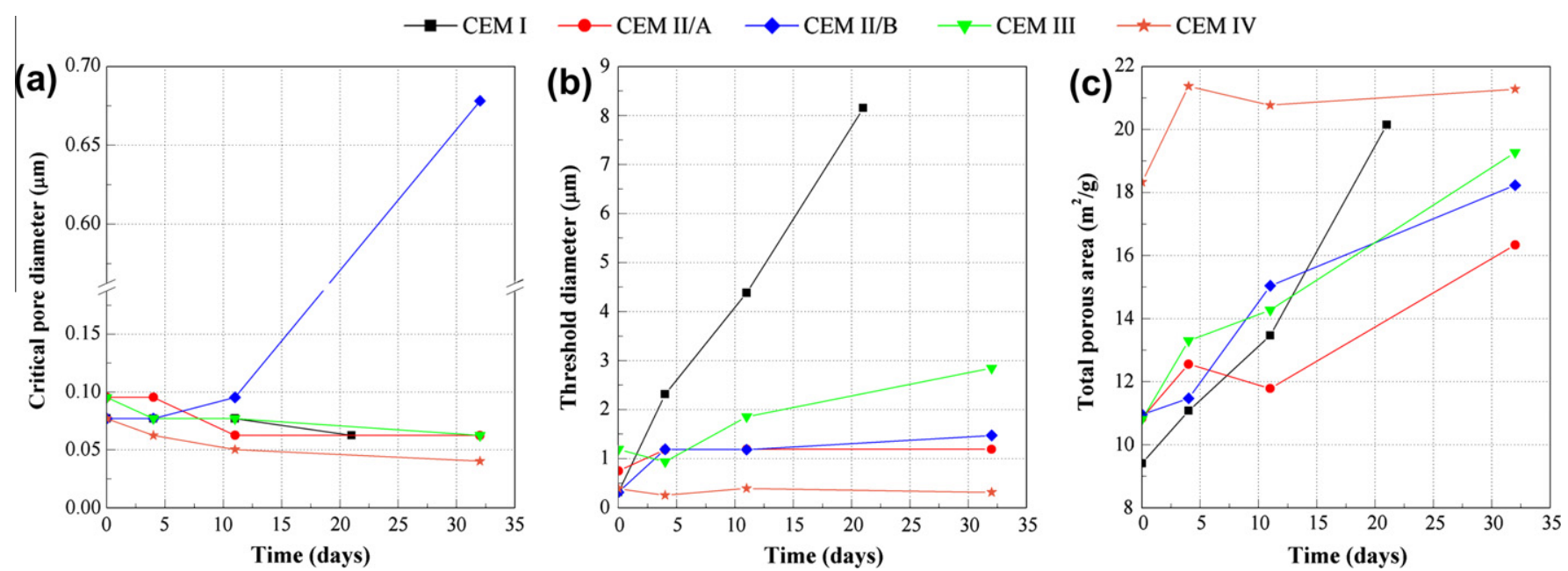

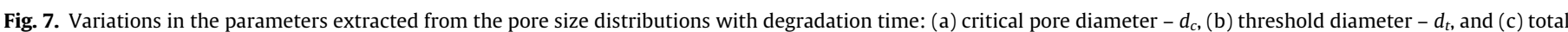
porous area $-A_{p}$.
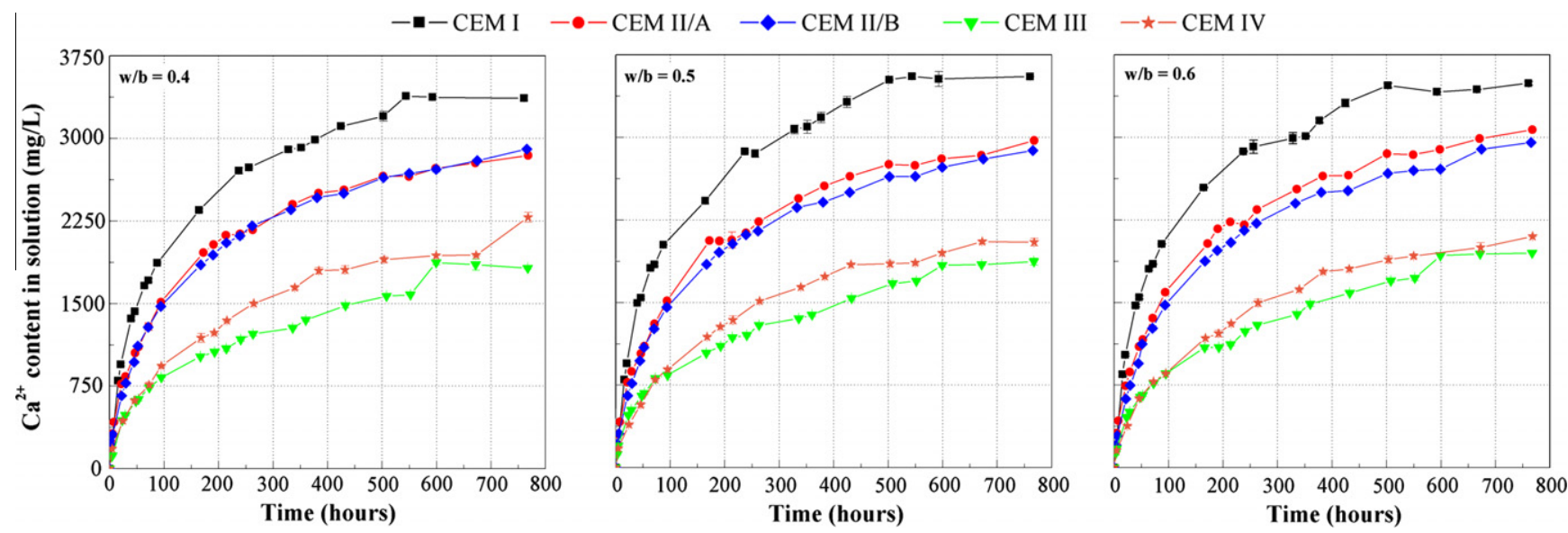

Fig. 8. Variations in the $\mathrm{Ca}^{2+}$ content in solution with degradation time, for each cement type and w/b ratio.

will be the total calcium dissolved, although the degradation front can advance further inward into those samples.

This results can be explained by considering the $\mathrm{Ca} / \mathrm{Si}$ ratio of the cementitious matrix, as it controls the decalcification process, as showed by Berner [1] and Gérard [10]. As far as the content of portlandite in the cementitious matrix is reduced by the decalcification process, the degradation grade will be controlled by the $\mathrm{Ca} /$ $\mathrm{Si}$ ratio of the $\mathrm{C}-\mathrm{S}-\mathrm{H}$ gel. Faucon and Revertegat [51,57] also showed that when the $\mathrm{Ca} / \mathrm{Si}$ ratio of the $\mathrm{C}-\mathrm{S}-\mathrm{H}$ gel diminishes, its resistance to the decalcification process increases. The $\mathrm{Ca} / \mathrm{Si}$
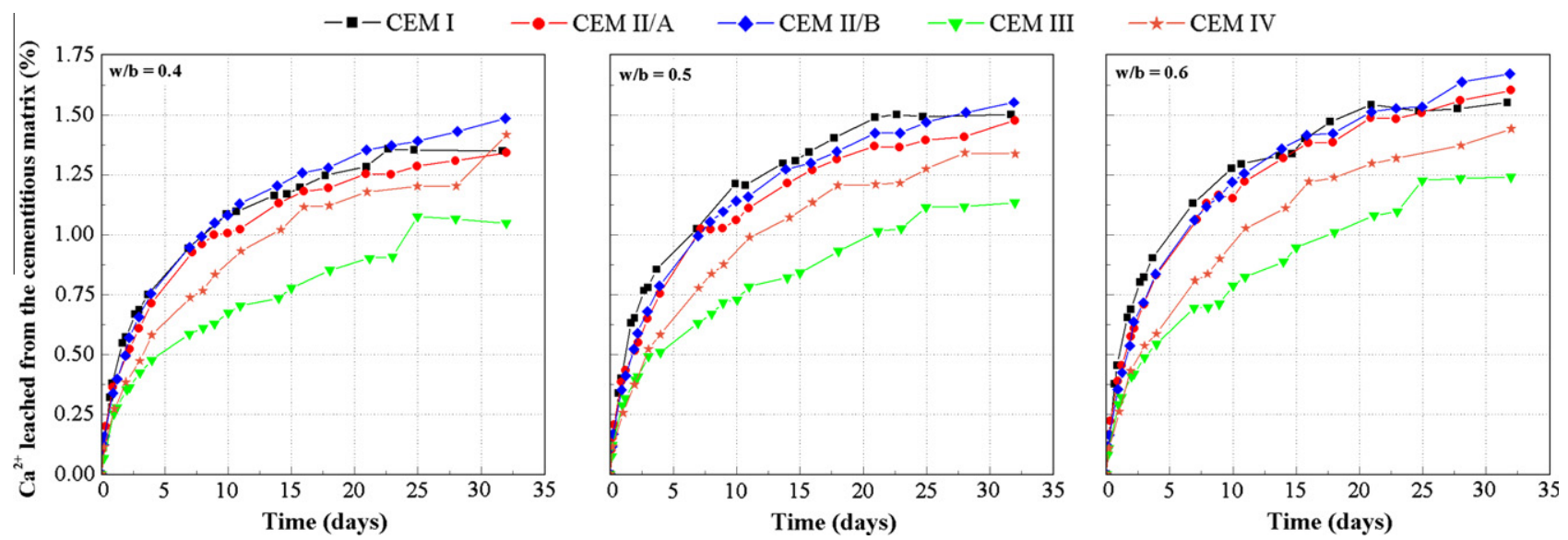

Fig. 9. Percentage of $\mathrm{Ca}^{2+}$ leached with degradation time, for each cement type and w/b ratio. 
Table 5

Average ultrasonic velocity of the native samples, for each cement type and w/b ratio.

\begin{tabular}{llll}
\hline Cement type & \multicolumn{2}{l}{$\begin{array}{l}\text { Average ultrasonic velocity }(\mathrm{m} / \mathrm{s}) \\
\text { w/b ratio }\end{array}$} & \\
\cline { 2 - 4 } & 0.4 & 0.5 & 0.6 \\
\hline CEM I & $4627 \pm 8$ & $4340 \pm 26$ & $4138 \pm 42$ \\
CEM II/A & $4604 \pm 3$ & $4310 \pm 9$ & $4064 \pm 12$ \\
CEM II/B & $4639 \pm 64$ & $4333 \pm 44$ & $4112 \pm 25$ \\
CEM III & $4560 \pm 8$ & $4260 \pm 52$ & $4067 \pm 54$ \\
CEM IV & $4642 \pm 20$ & $4420 \pm 44$ & $4058 \pm 143$ \\
\hline
\end{tabular}

ratio of the hydrates in a pure Portland cementitious matrix is reduced by the presence of additions, as fly ash or blast-furnace slag [58,59]: from a mean value of $1.8-2.0$, to average values of 1.32 for fly-ash and 1.29 for blast-furnace slag. Although the $\mathrm{Ca} /$ $\mathrm{Si}$ ratios of the hydrates may have been lowered in the samples with mineral additions, the $\mathrm{Ca} / \mathrm{Si}$ ratio in hydrates will probably not be different from one type of addition to another. EscalanteGarcía et al. [60] reported degrees of reaction of $20-30 \%$ after 28 days for slags blended with OPC in similar conditions as in our work; they showed that the degree of reaction increases with the amount of slag. Similar results (degree of reaction of 30-55\%) were found by Lumley et al. [61]. Zhang et al. [62] showed that the degree of reaction of fly-ash blended with OPC is reduced as the content of fly-ash increases. Also, Feng et al. [63] and Pane and Hansen [64] reported larger degree of reaction of slag, when comparing with fly-ash after 28 days. Therefore, the hydration rate of the additions may be playing the major role in the variations of the percentage of $\mathrm{Ca}^{2+}$ leached and thus in the degradation grade of the samples.

\subsection{Non-destructive ultrasonic characterisation}

There is no significant influence of the cement type on the average ultrasonic velocity of the native samples (see Table 5). For a given $\mathrm{w} / \mathrm{b}$ ratio, the relative differences that can be found among each cement type are no larger than $1 \%$ (except for the cement type IV with a w/b ratio of 0.5 ). However, there is a strong influence of the $\mathrm{w} / \mathrm{b}$ ratio on the average ultrasonic velocity of the native samples. For all cement types, the ultrasonic velocity decreases as the $\mathrm{w} / \mathrm{b}$ ratio increases. Such variation can be explained by the increase in both the porosity and hydrated products content per volume (and a decrease in the aggregate content) $[21,22,65]$, caused by the $\mathrm{w} / \mathrm{b}$ increase.

The relative decrease of the ultrasonic velocity $(\Delta \widehat{V})$ will be analysed to compare the variations in the ultrasonic velocity by the decalcification process (see Fig. 10). As seen in the porosity variations (see Fig. 5) an arrangement of the relative ultrasonic velocity decrease according to the cement type can be observed. Samples with higher initial calcium contents exhibit higher $\Delta \widehat{V}$ values and thus higher degradation grades. Also, as far as the w/b ratio increases the differences between the samples are larger. Considering the principles of the Elasticity Theory, it is possible to express the longitudinal ultrasonic velocity $\left(V_{l}\right)$ of a given material as a function of the apparent density of the material $(\rho)$, its elastic modulus $(E)$ and the Poisson ratio $(\mu)$ :

$V_{l}=\sqrt{\frac{E \cdot(1-\mu)}{\rho \cdot(1+\mu) \cdot(1-2 \cdot \mu)}}$

The variations in the ultrasonic velocity by the decalcification process are mainly influenced by the open water porosity and the initial calcium content of the samples. The results of previously published works [27] showed that the elastic constants of the degraded cementitious matrix are proportional to the open porosity of the material. In addition, the initial calcium of the samples influences the amount of calcium to be leached and thus the loss of elastic parameters of the cementitious matrix.

\subsection{Modelling the degradation process}

The previous sections presented the modification of the samples microstructure by the degradation process, and which factors may be controlling the kinetics and the extent of the degradation process. Many factors (porosity, initial calcium content, etc.) influence the degradation process. The present section aims to model both the kinetics of the degradation process and the degradation grade of the samples, using accessible microstructural parameters of the native material. The decalcification kinetics will be modelled using an analytical solution of the Fick's second law of diffusion [66]; it will be assumed that the rate of leaching follows a square root of time. The degradation grade of the materials will be accounted by the ultrasonic velocity of the degraded material and further modelling will be done by applying the shrinking unreacted-core approach [67,68].
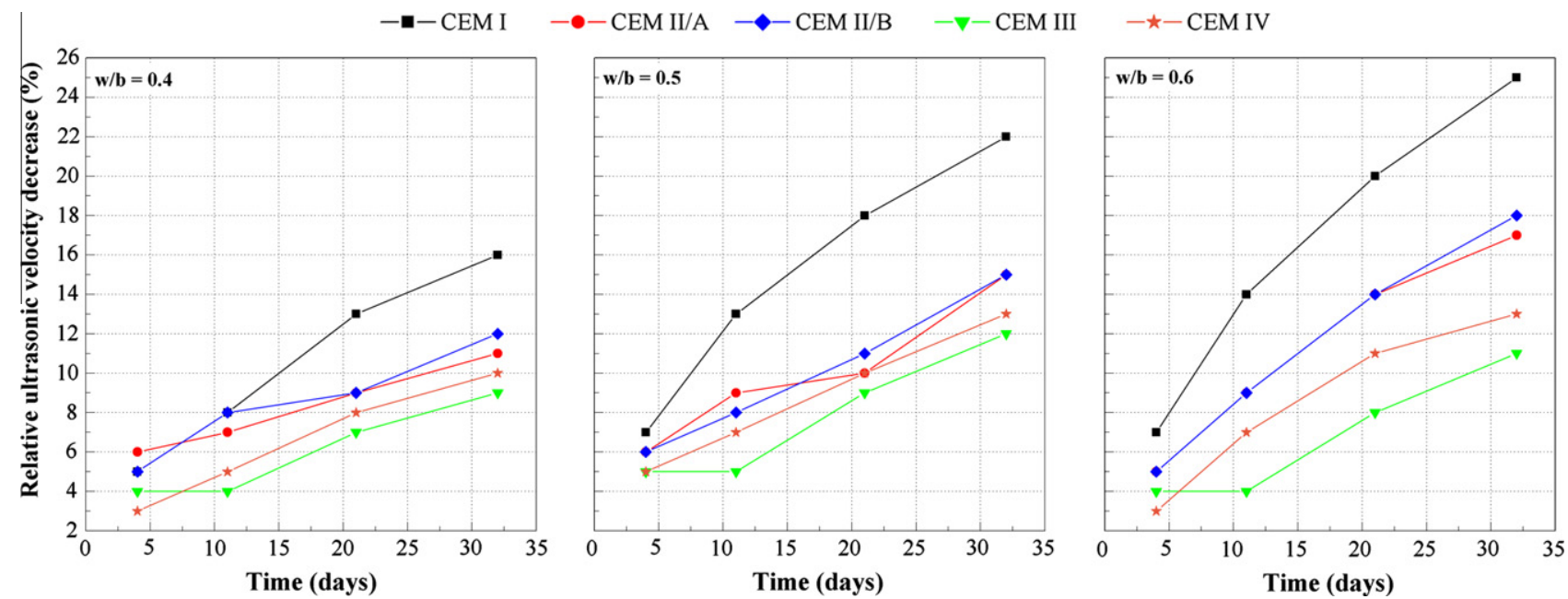

Fig. 10. Variations in $\Delta \widehat{V}$ with the degradation time, for each cement type and $\mathrm{w} / \mathrm{b}$ ratio. 
Table 6

Kinetic parameters and corresponding $R^{2}$ statistical obtained by adjusting the experimental degraded depths with the square root of time.

\begin{tabular}{llll}
\hline Cement type & w/b Ratio & $a\left(\mathrm{~mm}^{2} /\right.$ day $)$ & $R^{2}$ \\
\hline CEM I & 0.4 & 1.34 & 0.99 \\
& 0.5 & 1.86 & 0.95 \\
CEM II/A & 0.6 & 1.79 & 0.97 \\
& 0.4 & 1.17 & 0.98 \\
CEM II/B & 0.5 & 1.64 & 0.95 \\
& 0.6 & 1.52 & 0.98 \\
CEM III & 0.4 & 1.16 & 0.96 \\
& 0.5 & 1.60 & 0.99 \\
CEM IV & 0.6 & 1.68 & 0.98 \\
& 0.4 & 1.12 & 0.97 \\
& 0.5 & 1.43 & 0.99 \\
& 0.6 & 1.69 & 0.97 \\
& 0.4 & 1.28 & 0.99 \\
& 0.5 & 1.41 & 0.99 \\
& 0.6 & 1.81 & 0.99 \\
\hline
\end{tabular}

\subsection{Degradation process kinetics}

From among the variables amenable to be described by the Fick's second law of diffusion, we have chosen the average degraded depth, $\hat{e}_{D}$, because it is easy to measure and describe the fraction (either area or volume) of degraded material. Some simplifications must be considered: the main process that controls the kinetics of the decalcification process is the diffusion of the ions, the decalcification process is assumed to be one-dimensional, and only one diffusive ion is considered. Thus, an analytical solution to the Fick's law can be obtained [66]:

$\hat{e}_{D}=a \cdot \sqrt{t}$

where $\hat{e}_{D}$ is the degraded depth, $t$ the degradation time and $a$ the kinetic parameter of the decalcification process. The kinetic parameters for each cement type and $\mathrm{w} / \mathrm{b}$ ratio can be obtained by adjusting the experimental measurements of $\hat{e}_{D}$ (Fig. 4) to a square-root time law, by the least-squares method (see Table 6). These parameters are similar to those reported in $[11,19,36]$. The goodness of the fits is shown by each $R^{2}$ statistical; the values of $R^{2}$ prove that, at least for the time considered in the present study, it is possible to use Eq. (8) to model the kinetics of the decalcification process.

The following stage is to relate the kinetic parameter of Eq. (8), $a$, with accessible microstructural parameters of the native material. The only reference found of similar models in the litera- ture owes to Kamali et al. $[18,19]$, although it is far away from being a general equation. They modelled the kinetic parameter $a$ as a product of weight independent functions $f, i$ and $j$, accounting for parameters of the material and the environment: $w / c$ ratio, experiment temperature and leaching protocol. In our study, several microstructural parameters were used and related to the kinetic parameters shown in Table 6 , using a multiple regression method. Such method was preferred to the simple linear regression method, because it involves several parameters that could influence the kinetics of the process. The parameters chosen were the initial calcium concentration $\left(\left[\mathrm{CaO}_{c}\right]\right)$, the open porosity of the bulk sample $(\phi)$, the open porosity of the cementitious matrix $\left(\phi_{m}\right)$, the volume fraction of the cementitious matrix $\left(\zeta_{m}^{S}\right)$ and the connectivity of the porous system $(\beta) . \phi_{m}$ was easily obtained by weighting $\phi$ with $\zeta_{m}^{S} . \beta$ is a parameter that accounts for the tortuosity and constrictivity of the pore network; it was obtained from the MIP analyses using the methodology described by Katz and Thompson $[54,56,69] .\left[\mathrm{CaO}_{c}\right]$ is considered an estimator of the calcium that may be leached, independently of the hydrated compound nature; the $\mathrm{CaO}$ content of the binder it is already used for modelling carbonation phenomena [70-72]. The porosity and the connectivity of the porous system are estimators of the porous system permeability, and the volume fraction of cementitious matrix accounts for the dilution effect of the aggregates in the permeability of the system.

The multiple regression method was applied using a step selection algorithm. This algorithm looks for the best-fit model using only the statistically significant variables, which were in turn identified by the $F$ test. A parameter will be added to the model in a given step if its $F$ value is larger than a specified value, which in this case is set to 4 . The final output of the adjustment made by the multiple regression method is Eq. (9), with two quantitative factors: the open porosity of the bulk material $(\phi)$ and the $\mathrm{CaO}$ concentration $\left(\left[\mathrm{CaO}_{c}\right]\right)$.

$a=0.07693 \cdot\left[\mathrm{CaO}_{c}\right]+9.17538 \cdot \phi-0.45946$

The values of the kinetic parameter $a$ estimated by Eq. (9) are compared with those obtained from the experimental degraded depths (Fig. 11a) as can be seen in Fig. 11a. The statistical parameters obtained after the adjustment (associated $p$-value, $R^{2}$ and residual; see Fig. 11a), and the analysis of the residuals (Fig. 11b), evidence that Eq. (9) provides a good estimate of the kinetic parameter $a$. Eventually, just by substituting Eq. (9) in Eq. (8) it is possible to obtain an expression to estimate for each time the average degraded depth (Fig. 12). A good correlation can be found
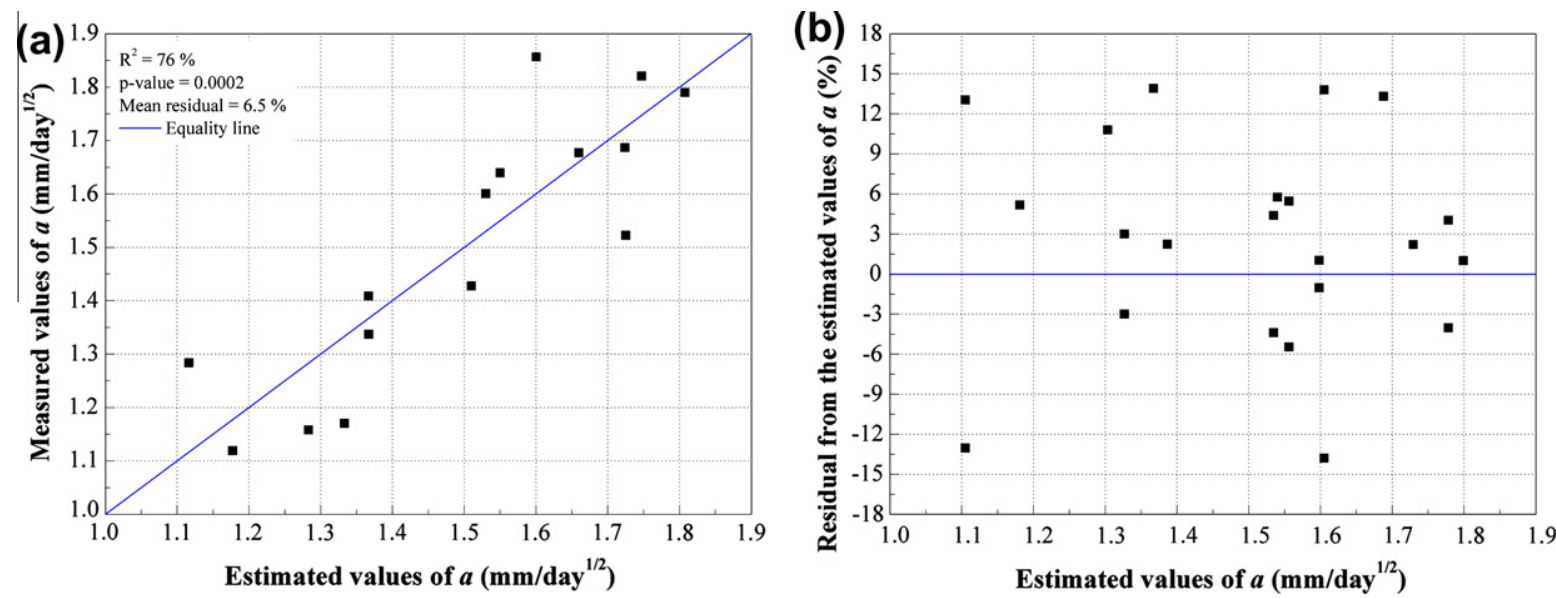

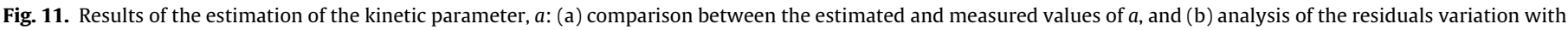
each estimated value of $a$. 


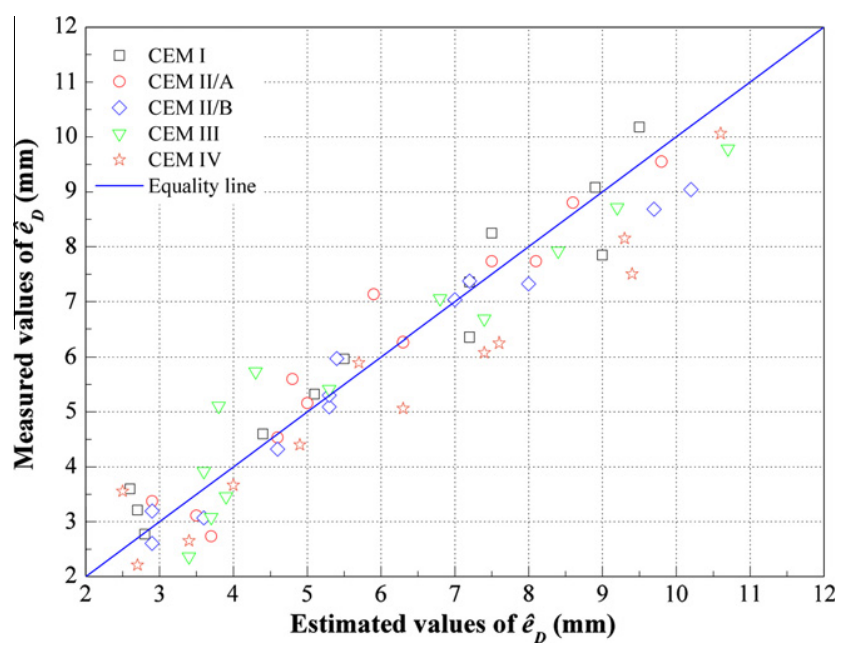

Fig. 12. Comparisons between the values of $\hat{e}_{D}$ estimated using Eq. (9) and the values of $\hat{e}_{D}$ measured by the phenolphthalein test.

between the estimated values of $\hat{e}_{D}$ and the values measured by the phenolphthalein test. The mean error made in the estimation of $\hat{e}_{D}$ is about $10 \%$.

To validate the results presented in this paper, Eq. (9) was used to estimate the decalcification kinetics available on similar studies from the literature i.e. cement mortar or concrete made from siliceous aggregates, and ammonium nitrate as aggressive agent $[28,31,42,73-75]$. The estimations made, as well as the parameters of the studies, are shown in Table 7 . The accuracy of the estimations is in good agreement in general terms with the data, and in most of the cases studied it is under an acceptable error value around $10 \%$. It shall be addressed that in most cases, the estimations were made from data displayed in the graphs, since no other data were available or the data provided were not clear.

Some remarks should be made with respect to these results. First, most of the analysed studies did not employ the same conditions to perform the porosity measurements: for instance, drying is made at a temperature of $60^{\circ} \mathrm{C}[28], 105^{\circ} \mathrm{C}[31,74]$, and $110^{\circ} \mathrm{C}$ $[73,75]$. A variation in approximately $1 \%$ of porosity is related to variations in the kinetic parameter of about $5 \%$. Second, even though numerous studies employ phenolphthalein to reveal the degraded zone, few indications are given on the method employed to measure the degraded depth: they are made using a common ruler [28], or using a video-microscope [31,73-75]. The huge influence of the degraded depth measurements in the error made in the estimations of the kinetic parameter was already shown in the above paragraphs. Lastly, some of the kinetics parameters available in the literature are surprising. The kinetic parameter for mortar decalcification showed by Nguyen et al. $[73,75]$ is even greater than the kinetic parameters of cement pastes that can be found in the literature $[19,36]$. It is also remarkable the high value obtained for the degradation kinetics of a mortar with $\mathrm{w} / \mathrm{b}$ ratio of 0.3 by Lafhaj and Goueygou [28], as well as the low value of the kinetic parameter presented by Perlot et al. [31] for a mortar with such a great porosity value.

\subsection{Degradation grade}

As stated in Section 3.5, the ultrasonic velocity can be considered an accurate measurement of the degradation grade of cementitious materials subjected to decalcification processes, as it accounts for the porosity and the elastic parameters of the material. The key is to identify an ultrasonic parameter of the degraded materials, which accounts for the loss of elastic properties of the material. Previous results [29] allows us to apply the shrinking unreacted-core model (SCM), proposed by Hinsenveld and Bishop $[67,68]$ to our samples. This model has been used by many authors to describe leaching degradation in cementitious materials [76-78], carbonation [70] or even the hydration of cementitious materials [79]. Under such scheme we can ideally assume the decalcified mortar as a composite biphasic material The first phase is an outer degraded zone $(D)$, with a given average thickness $\hat{e}_{D}$ and an average ultrasonic velocity $\widehat{V}_{D}$; the second phase is an inner sound zone $(U)$ with a given average thickness $\hat{e}_{U}$ and an average ultrasonic velocity $\widehat{V}_{U}$, assumed to be equal to $\widehat{V}_{0}$, the average ultrasonic velocity of the native material. Further details on the scheme used to calculate $\widehat{V}_{D}$ using the ultrasonic velocity measurements are given in [29]. Therefore, the ultrasonic velocity of the degraded mortar can be calculated using the following equation:

$V_{D}=\frac{\widehat{V}_{t} \cdot\left(2 \cdot \hat{e}_{D}+\hat{e}_{U}\right)-\hat{e}_{U} \cdot \widehat{V}_{0}}{2 \cdot \hat{e}_{D}}$

Table 7

Estimations of the kinetic parameters extracted from the literature using Eq. (11).

\begin{tabular}{|c|c|c|c|c|c|}
\hline Reference & Parameters of the study & & Degradation kinetics (mm day ${ }^{-1 / 2}$ ) & Estimated kinetics $\left(\mathrm{mm} \mathrm{day}^{-1 / 2}\right)$ & Error $(\%)$ \\
\hline \multirow[t]{4}{*}{ Lafhaf et al. [28] } & CEM I 52.5 - mortar & $\begin{array}{l}\mathrm{w} / \mathrm{b} 0.3 \\
\phi=12.3 \%\end{array}$ & 1.78 & 1.26 & 29 \\
\hline & & $\begin{array}{l}\mathrm{w} / \mathrm{b} 0.4 \\
\phi=15 \%\end{array}$ & 1.65 & 1.51 & 8 \\
\hline & & $\begin{array}{l}\text { w/b } 0.5 \\
\phi=15.9 \%\end{array}$ & 1.80 & 1.59 & 12 \\
\hline & $\begin{array}{l}\mathrm{w} / \mathrm{b} \text { ratio: } 0.3-0.6 \\
{\left[\mathrm{CaO}_{c}\right]=7.6803 \mathrm{M}}\end{array}$ & $\begin{array}{l}\mathrm{w} / \mathrm{b} 0.6 \\
\phi=18.2 \%\end{array}$ & 1.87 & 1.80 & 4 \\
\hline \multirow[t]{2}{*}{ Perlot et al. [31,74] } & $\begin{array}{l}\text { CEM I } 52.5-\text { mortar } \\
{\left[\mathrm{CaO}_{c}\right]=7.119 \mathrm{M}}\end{array}$ & $\begin{array}{l}\mathrm{w} / \mathrm{b} 0.43 \\
\phi=16 \%\end{array}$ & 1.63 & 1.56 & 4 \\
\hline & $\begin{array}{l}\text { CEM V/A } 42.5 \text { - mortar } \\
{\left[\mathrm{CaO}_{c}\right]=5.643 \mathrm{M}}\end{array}$ & $\begin{array}{l}\text { w/b } 0.41 \\
\phi=19 \%\end{array}$ & 1.4 & 1.71 & 22 \\
\hline \multirow[t]{2}{*}{ Nguyen et al. [73,75] } & $\begin{array}{l}\text { CEM I } 52.5 \text { - concrete } \\
{\left[\mathrm{CaO}_{c}\right]=7.8796}\end{array}$ & $\begin{array}{l}\mathrm{w} / \mathrm{b} 0.6 \\
\phi=16 \%{ }^{\mathrm{a}}\end{array}$ & 1.73 & 1.62 & 6 \\
\hline & $\begin{array}{l}\text { CEM I } 52.5-\text { mortar } \\
{\left[\mathrm{CaO}_{c}\right]=7.19 \mathrm{M}}\end{array}$ & $\begin{array}{l}\text { w/b } 0.6 \\
\phi=19 \%\end{array}$ & 2.40 & 1.84 & 23 \\
\hline Le Bellego [42] & $\begin{array}{l}\text { CEM I } 42.5-\text { mortar } \\
{\left[\mathrm{CaO}_{c}\right]=6.985 \mathrm{M}}\end{array}$ & $\begin{array}{l}\text { w/b } 0.4 \\
\phi=18.2 \%\end{array}$ & 1.60 & 1.75 & 9 \\
\hline
\end{tabular}

\footnotetext{
a Porosity of concrete was not provided by the authors, hence a value of $16 \%$ was adopted.
} 


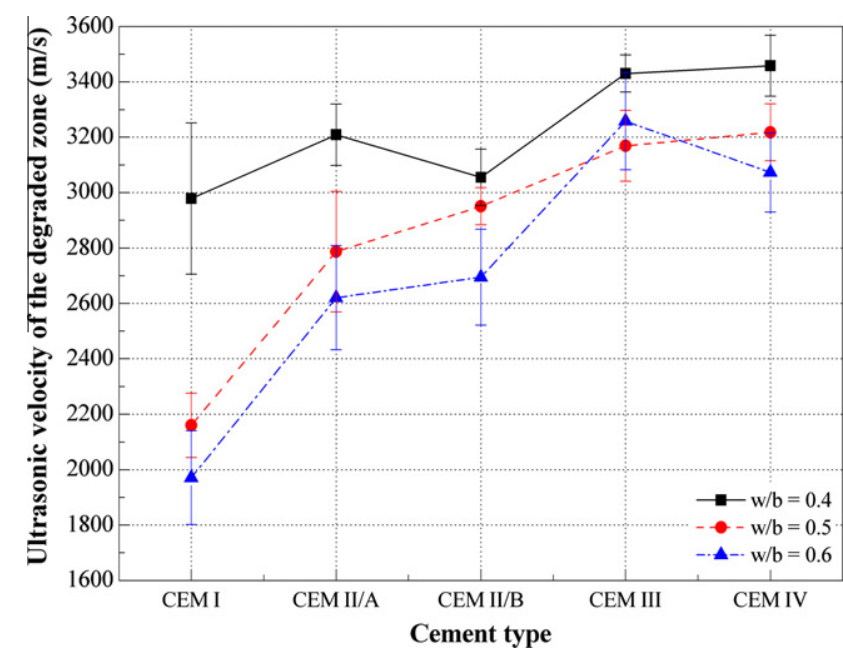

Fig. 13. Average values of $\widehat{V}_{D}$, as a function of the cement type and the w/b ratio.

Assuming that $V_{D}$ is almost invariant with the degradation time, its average value can be calculated $\left(\widehat{V}_{D}\right)$, see Fig. 13 . The mean relative variations of $\widehat{V}_{D}$ observed within each class (cement type and $\mathrm{w} / \mathrm{b}$ ratio) are not greater than $7 \%$, diminishing as the degradation time increases and the degraded zone increases. Such variations are mainly due to the error made in the degraded depth measurements as well as to neglecting the degradation front thickness. As the degraded depths in the samples with 4 and 11 days of degradation were equal or less than $6 \mathrm{~mm}$, the uncertainty of the $V_{D}$ values at those degradation times is close to $10 \%$.

As both the $\mathrm{CaO}$ content and the w/b ratio increase, $\widehat{V}_{D}$ decreases (Fig. 13). Both factors ( $\mathrm{CaO}$ content and w/b ratio) influence the cementitious matrix in a similar way: with their increase, the cementitious matrix will have more "leachable" calcium and thus the loss of elastic properties will become greater. As mentioned earlier, the $\mathrm{CaO}$ content of the samples controls the quantity of calcium that may be leached from the cementitious matrix. Furthermore, the increase of the $\mathrm{w} / \mathrm{b}$ ratio will promote the hydration of the cementitious matrix. It can be seen that whenever the $\mathrm{CaO}$ content increases, the associated decrease in $\widehat{V}_{D}$ when the w/b ratio increases is greater. From the above-mentioned questions, it can be appreciated the capability of $\widehat{V}_{D}$ to account for the degradation grade of the materials, including the effect of varying the $\mathrm{w} / \mathrm{b}$ ratio and the cement type.

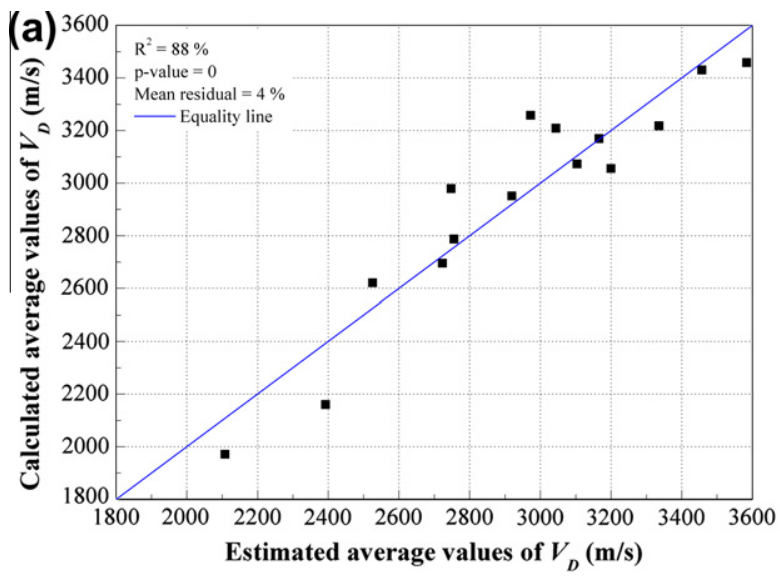

Subsequently $\widehat{V}_{D}$ will defined using a set of microstructural parameters of the native material. The selected parameters are: the $\mathrm{CaO}$ concentration $\left(\left[\mathrm{CaO}_{c}\right]\right)$, the volume fraction of the cementitious matrix $\left(\zeta_{m}^{S}\right)$, and the open porosity $(\phi)$ of the native mortar. Those parameters were chosen since they clearly influence the ultrasonic velocity. The influence of the initial calcium content was already discussed in Section 3.5; the volume fraction of cementitious matrix in the native material is used to account for the content of cementitious matrix, and therefore weight the effect of the decalcification process in the ultrasonic velocity. A simple linear regression will be used to relate $\widehat{V}_{D}$ and the chosen parameters, since Eq. (7) showed a linear relation between $E$ and $V_{l}$. To facilitate the statistical analysis, a combination of the parameters listed above is used, obtaining a new parameter called the accessible calcium content of the cementitious matrix, $\mathrm{Ca}_{a c c}$, described by the following equation:

$\mathrm{Ca}_{a c c}=\phi \cdot \zeta_{m}^{s} \cdot\left[\mathrm{CaO}_{c}\right]$

The linear regression made with the whole set of values allowed to obtain the following equation:

$\widehat{V}_{D}=5180.41-11140.44 \cdot \mathrm{Ca}_{a c c}$

The statistical parameters obtained after the adjustment (associated $p$-value, $R^{2}$ and residual, see Fig. $14 \mathrm{a}$ ), and the analysis of the residuals (Fig. 14b) evidence that Eq. (12) provide a good estimation of $\widehat{V}_{D}$. The comparison between the values of $\widehat{V}_{D}$ estimated by Eq. (12) and the values of $\widehat{V}_{D}$ calculated by Eq. (10) can be seen in Fig. 14a.

Eventually, it is possible to measure the degraded depth in a non-destructive way using ultrasonic velocity measurements of the samples at each degradation time. This can be done by just assuming that the average thickness of the sound zone $\left(\hat{e}_{U}\right)$ may be estimated from the degraded depth $\left(\hat{e}_{D}\right)$ and the average thickness of the sample $(\hat{e})$, under the SCM scheme:

$\hat{e}_{U}=\hat{e}-2 \cdot \hat{e}_{D}$

Just by substituting Eq. (13) in Eq. (10), and isolating $\hat{e}_{D}$, an expression of the degraded depth can be obtained as a function of the average thickness of the sample $(\hat{e})$, the ultrasonic velocity of the native material $\left(\widehat{V}_{0}\right)$, the ultrasonic velocity at each degradation time $\left(\widehat{V}_{t}\right)$ and the ultrasonic velocity of the degraded material $\left(\widehat{V}_{D}\right)$, as.

$\hat{e}_{D}=\frac{\hat{e} \cdot\left(\widehat{V}_{0}-\widehat{V}_{t}\right)}{2 \cdot\left(\widehat{V}_{0}-\widehat{V}_{D}\right)}$

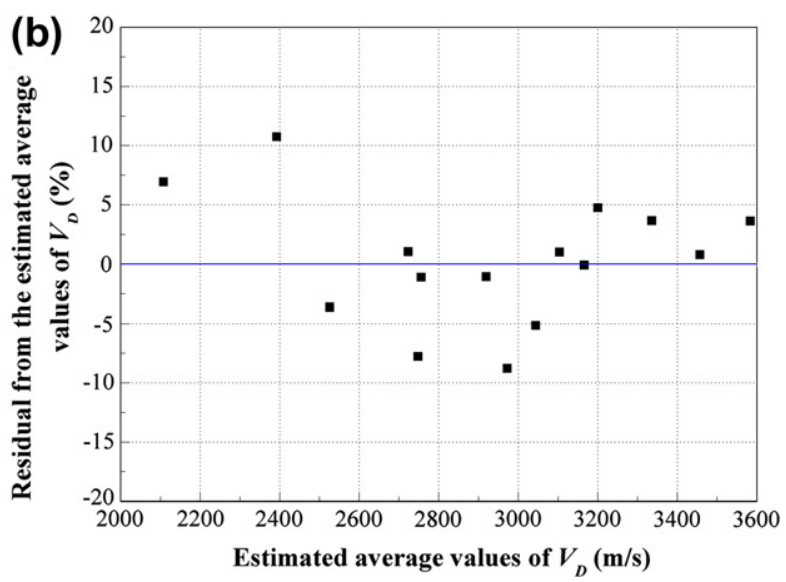

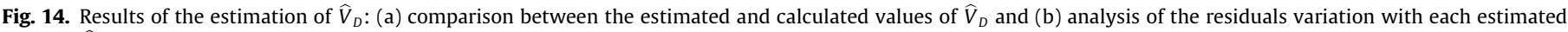
value of $\widehat{V}_{D}$. 


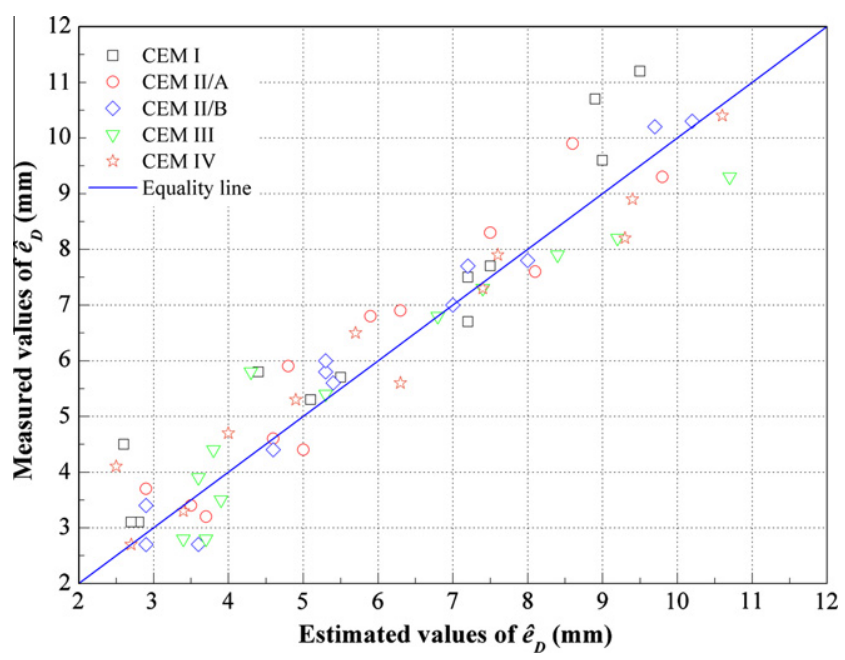

Fig. 15. Comparisons between the values of $\hat{e}_{D}$ estimated using Eq. (14) and the values of $\hat{e}_{D}$ measured by the phenolphthalein test.

It is therefore possible to estimate the degraded depth by means of non-destructive measurements, as $\hat{e}, \widehat{V}_{0}$ and $\widehat{V}_{t}$ can be measured and $\widehat{V}_{D}$ may be estimated with Eq. (12). Again, good correlations between the estimated and measured values of $\hat{e}_{D}$ (Fig. 15a) can be observed, with the main error of the estimations close to $10 \%$.

\section{Conclusions}

The results of a thorough microstructural characterisation of a set of decalcified cement mortars have been presented in this paper. The main factor that controls the advance of the degradation process, during its initial stages, is the neutralisation capacity of the material, which depends on the initial calcium content of the samples. The variations in the degraded depth, in respect of both the $\mathrm{w} / \mathrm{b}$ ratio and the cement type, showed that when the $\mathrm{w} / \mathrm{b}$ ratio increases, samples with lower initial calcium contents exhibit higher degraded depths during the initial stages of the degradation process. The degradation grade of the samples accounted for the variations in the porous microstructure, the percentage of $\mathrm{Ca}^{2+}$ leached and the variations in the ultrasonic velocity of the samples; it was shown that the degradation grade of each sample depends upon the initial calcium contents, but it is also influenced by the porosity of the native samples and the degree of the hydration reactions. The ultrasonic velocity was chosen as a good estimator of the degradation grade, since the variations in the elastic parameters of the materials were largely influenced by the porosity and the initial calcium content of the samples. Furthermore, degradation process kinetics and the degradation grade of the materials have been estimated using accessible microstructural parameters from the native materials:

(a) The kinetics of the decalcification process, as expressed by Fick's second law of diffusion, has been described as a function of two variables of the native material (see Eq. (9)), namely: the open porosity $(\phi)$ and the $\mathrm{CaO}$ concentration $\left(\left[\mathrm{CaO}_{c}\right]\right)$. Furthermore, this approach was validated by estimating a set of kinetic parameters obtained from the literature. Reasonable estimations were obtained with a mean error value about $10 \%$. Further estimations of the average degraded depth at each degradation time were made with such an equation. These estimations correlated well with the average degraded depths measured by the phenolphthalein test, with a medium error of about $10 \%$. (b) The degradation grade of the materials is expressed as the ultrasonic velocity of the degraded material, $V_{D}$, which is calculated using the scheme of the shrinking unreacted-core model (SCM). This parameter is almost invariant with the degradation time, being an intrinsic characteristic of the material accounting for its degradation grade. $V_{D}$ has been described as a function of three parameters of the native material (Eq. (12)): the $\mathrm{CaO}$ concentration $\left(\left[\mathrm{CaO}_{c}\right]\right)$, the volume fraction of the cementitious matrix $\left(\zeta_{m}^{S}\right)$, and the open porosity $(\phi)$ of the native mortar. Furthermore, using the SCM scheme, the estimations of $V_{D}$, and ultrasonic inspections it was possible to measure the degraded depth at each degradation time. These estimations showed good correlations with the measured values and its main error is about $10 \%$.

The results obtained in this work suggest that using accessible parameters of the native materials, two main characteristics of the decalcification process can be modelled, i.e. the kinetics of the decalcification process and the degradation grade of the decalcified cement mortars. The equations presented in this paper (Eqs. (9) and (12)) provided estimations of the degraded depth with good agreement with experimental data from cementitious materials subjected to a decalcification process. Eventually, the use of precise ultrasonic characterisation techniques will allow monitoring and preventing failures under service of materials subjected to this kind of process.

\section{Acknowledgements}

Support from the Spanish Science and Innovation Ministry through research project BIA2009-14395-C04-01 is greatly acknowledged. Dr. I. Segura is supported by the postdoctoral Juan de la Cierva programme of the Spanish Ministry of Science and Innovation, Dr. M. Molero is supported by the department of education of the Community of Madrid and the European Social Fund, and Dr. S. Aparicio is supported by the postdoctoral JAE-DOC programme of the Spanish National Research Council (CSIC).

\section{References}

[1] Berner UR. Modelling the incongruent dissolution of hydrated cement minerals. Radiochim Acta 1988;44(45):387-93.

[2] Berner UR. Evolution of pore water chemistry during degradation of cement in a radioactive waste repository environment. Waste Manage 1992;12:201-19.

[3] Heukamp FH, Ulm F, Germaine JT. Mechanical properties of calcium-leached cement pastes. Triaxial stress states and the influence of the pore pressures. Cem Concr Res 2001;31:767-74.

[4] Haga K, Sutou S, Hironaga M, Tanaka S, Nagasaki S. Change in pore structure and composition of hardened cement paste during the process of dissolution. Cem Concr Res 2005;35:943-50.

[5] Hernández MG, Anaya JJ, Sanchez T, Segura I. Porosity estimation of aged mortar using a micromechanical model. Ultrasonics 2006;44(Suppl. 1). e1007e1.

[6] Agostini F, Lafhaj Z, Skoczylas F, Loodsveldt H. Experimental study of accelerated leaching on hollow cylinders of mortar. Cem Concr Res 2007;37(1):71-8.

[7] Glasser FP, Marchand J, Samson E. Durability of concrete - degradation phenomena involving detrimental chemical reactions. Cem Concr Res 2008;38(2):226-46.

[8] Adenot F, Buil M. Modelling of the corrosion of the cement paste by deionised water. Cem Concr Res 1992;22:489-96.

[9] Mainguy M, Tognazzi C, Torrenti J-M, Adenot F. Modelling of leaching in pure cement paste and mortar. Cem Concr Res 2000;30:83-90.

[10] Gérard B, Le Bellego C, Bernard O. Simplified modelling of calcium leaching of concrete in various environments. Mater Struct 2002;35(10):632-40.

[11] Moranville M, Kamali S, Guillon E. Physicochemical equilibria of cement-based materials in aggressive environments - experiment and modelling. Cem Concr Res 2004;34:1569-78.

[12] Samson E, Marchand J. Modelling the transport of ions in unsaturated cementbased materials. Comput Struct 2007;85(23-24):1740-56. 
[13] Le Bellego C, Pijaudier-Cabot G, Gérard B, Dubé J-F, Molez L. Coupled mechanical and chemical damage in calcium leached cementitious structures. J Eng Mech 2003;129(3):333-41.

[14] Constantinides G, Ulm F. The effect of two types of C-S-H on the elasticity of cement-based materials: results from nanoindentation and micromechanical modeling. Cem Concr Res 2004;34:67-80.

[15] Kuhl D, Bangert F, Meschke G. Coupled chemo-mechanical deterioration of cementitious materials. Part II: numerical methods and simulations. Int J Solids Struct 2004;41:41-67.

[16] Nguyen VH, Nedjar B, Torrenti JM. Chemo-mechanical coupling behaviour of leached concrete. Part II: modelling. Nucl Eng Des 2007;237(2021):2090-7

[17] Bernard F, Kamali-Bernard S, Prince W. 3D multi-scale modelling of mechanical behaviour of sound and leached mortar. Cem Concr Res 2008;38:449-58.

[18] Kamali S, Gérard B, Moranville M. Modelling the leaching kinetics of cementbased materials-influence of materials and environment. Cem Concr Compos 2003;25:451-8.

[19] Kamali S, Moranville M, Leclercq S. Material and environmental parameter effects on the leaching of cement pastes: experiments and modelling. Cem Concr Res 2008;38:575-85.

[20] Vergara L, Gosálbez J, Fuente JV, Miralles R, Bosch I. Measurement of cement porosity by centroid frequency profiles of ultrasonic grain noise. Signal Process 2004;84(12):2315-24

[21] Hernández MG, Anaya JJ, Ullate LG, Cegarra M, Sánchez T. Application of a micromechanical model of three phases to estimating the porosity of mortar by ultrasound. Cem Concr Res 2006;36(4):617-24.

[22] Hernández MG, Anaya JJ, Ullate LG, Ibañez A. Formulation of a new micromechanic model of three phases for ultrasonic characterization of cement-based materials. Cem Concr Res 2006;36(4):609-16.

[23] Saint-Pierre F, Rivard P, Ballivy G. Measurement of alkali-silica reaction progression by ultrasonic waves attenuation. Cem Concr Res 2007;37(6):948-56.

[24] Lafhaj Z, Goueygou M, Djerbi A, Kaczmarek M. Correlation between porosity, permeability and ultrasonic parameters of mortar with variable water/cement ratio and water content. Cem Concr Res 2006;36(4):625-33.

[25] Segura I, Sánchez E, Moragues A, Hernández MG. Assessment of mortar evolution in pig slurry by mechanical and ultrasonic measurements. Constr Build Mater. 2010;24(9):1572-9.

[26] Naffa SO, Goueygou M, Piwakowski B, Buyle-Bodin F. Detection of chemica damage in concrete using ultrasound. Ultrasonics 2002;40:247-51.

[27] Hernández MG, Anaya JJ, Sánchez T, Segura I. Porosity estimation of aged mortar using a micromechanical model. Ultrasonics 2006:44(1). e1007-e11.

[28] Lafhaj Z, Goueygou M. Experimental study on sound and damaged mortar: variation of ultrasonic parameters with porosity. Constr Build Mater 2009;23:953-8.

[29] Segura I, Moragues A, Macphee DE, Anaya JJ, Molero M. Study of the decalcification process in mortars degraded by $\mathrm{NH}_{4} \mathrm{NO}_{3}$ by using ultrasonic techniques. Mater Constr 2009;59(296):19-38.

[30] UNE-EN 197-1:2000 Cement. Part 1: composition, specifications and conformity criteria for common cements. In: AENOR, editor. AENOR; 2000. p. 30.

[31] Perlot C, Verdier J, Carcassès M. Influence of cement type on transport properties and chemical degradation: application to nuclear waste storage. Mater Struct 2006;39:511-23.

[32] Assié S, Escadeillas G, Waller V. Estimates of self-compacting concrete 'potential' durability. Constr Build Mater 2007;21(10):1909-17.

[33] Xie SY, Shao JF, Burlion N. Experimental study of mechanical behaviour of cement paste under compressive stress and chemical degradation. Cem Concr Res 2008;38(12):1416-23.

[34] Kaid N, Cyr M, Julien S, Khelafi H. Durability of concrete containing a natura pozzolan as defined by a performance-based approach. Constr Build Mater 2009;23(12):3457-67.

[35] Cardé C, Francois R, Torrenti J. Leaching of both calcium hydroxide and CSH from cement paste: modelling the mechanical behaviour. Cem Concr Res 1996;26(8):1257-68.

[36] Cardé C, Escadeillas G, Francois R. Use of ammonium nitrate solution to simulate and accelerate the leaching of cement pastes due to deionised water. Mag Concr Res 1997;49(181):295-301.

[37] Heukamp FH. Chemomechanics of calcium leaching of cement-based materials at different scales: the role of $\mathrm{CH}$-dissolution and $\mathrm{CSH}$ degradation on strength and durability performance of materials and structures. Massachusetts: Massachusetts Institute of Technology; 2003.

[38] Segura I. Characterization of the decalcification process in mortars by means of destructive and non-destructive testing. Madrid: Polytechnic University of Madrid; 2008.

[39] Ramachandran VS, Beaudoin JJ. Handbook of analytical techniques in concrete science. Norwich, New York: William Andrew Publishing; 2001.

[40] Beddoe RE, Dorner HW. Modelling acid attack on concrete: part I. The essential mechanisms. Cem Concr Res 2005;35:2333-9.

[41] Torrenti JM, Nguyen VH, Colina H, Le Maou F, Bendoudjema F, Deleruyelle F. Coupling between leaching and creep of concrete. Cem Concr Res 2008;38(6):816-21.

[42] Le Bellego C. Couplage chimie-mecanique dans les structures en beton attaquees par l'eau: etude experimentale et analyse numerique. Cachan: Ecole Normale Superieure de Cachan; 2001.
[43] Segura I, Molero M, Aparicio S, Moragues A. Measurement of the degraded depth in cementitious materials by automatic digital image processing. Meas Sci Technol 2010;21(5):055103.

[44] Cardé C, Francois R. Effect of the leaching of calcium hydroxide from cement paste on mechanical and physical properties. Cem Concr Res 1997;27(4):539-50.

[45] Bertron A, Duchesne J, Escadeillas G. Accelerated tests of hardened cement pastes alteration by organic acids: analysis of the $\mathrm{pH}$ effect. Cem Concr Res 2005;35(1):155-66.

[46] RILEM-TC/14-CPC. CPC 11.3 Absorption d'eau par immersion sous vide/ absorption of water by immersion under vacuum. Mater Struct 1984; 17(101): 391-4.

[47] García de Arriba R, Sagrado JD, Madrazo JAP. Determinación de la porosidad y la permeabilidad del hormigón endurecido. Hormigón Acero 1994;193:105-16.

[48] Rootare HM, Prenzlow CF. Surface areas from mercury intrusion porosimeter measurements. J Phys Chem 1967;71(8):2733-6.

[49] Glass GK, Reddy B, Buenfeld NR. Corrosion inhibition in concrete arising from its acid neutralisation capacity. Corros Sci 2000;42(9):1587-98.

[50] Lagerblad B. TR-01-27 leaching performance of concrete based on studies of samples from old concrete constructions. Stockholm: Swedish Cement and Concrete Research Institute; 2001. p. 83.

[51] Faucon P, Adenot F, Jacquinot JF, Petit JC, Cabrillac R, Jorda M. Long-term behaviour of cement pastes used for nuclear waste disposal: review of physico-chemical mechanisms of water degradation. Cem Concr Res 1998;28(6):847-57.

[52] Haga K, Sutou S, Hironaga M, Tanaka S, Nagasaki S. Effects of porosity on leaching of Ca from hardened ordinary Portland cement paste. Cem Concr Res 2005;35(9):1764-75.

[53] Cassagnabère F, Verdier J. Effect of $\mathrm{w} / \mathrm{c}$ ratio on of physical properties of totally decalcified mortars degraded with ammonium nitrate. In: Alexander MG, Bertron A, editors. Concrete in aggressive aqueous environments performance, testing and modeling. Toulouse: Rilem; 2009. p. 65-77.

[54] Katz AJ, Thompson AH. Prediction of rock electrical conductivity from mercury injection measurements. J Geophys Res 1987;92(B1):599-607.

[55] Winslow D, Diamond S. A mercury porosimetry study of the evolution of porosity in portland cement. ASTM J Mater 1970;5(3):564-85.

[56] Nokken MR, Hooton RD. Using pore parameters to estimate permeability and conductivity of concrete. Mater Struct 2008;41:1-16.

[57] Revertegat E, Richet C, Gégout P. Effect of pH on the durability of cement pastes. Cem Concr Res 1992;22:259-72.

[58] Taylor HFW. Cement chemistry. 2nd ed. London: Thomas Telford Publishing; 2003.

[59] Duchesne J, Bérubé MA. Effect of supplementary cementing materials on the composition of cement hydration products. Adv Cem Mater 1995;2(2):43-52.

[60] Escalante-García JI, Gómez LY, Johal KK, Mendoza G, Mancha H, Méndez J. Reactivity of blast-furnace slag in Portland cement blends hydrated under different conditions. Cem Concr Res 2001;31(10):1403-9.

[61] Lumley JS, Gollop RS, Moir GK, Taylor HFW. Degrees of reaction of the slag in some blends with Portland cements. Cem Concr Res 1996;26(1):139-51.

[62] Zhang YM, Sun W, Yan HD. Hydration of high-volume fly ash cement pastes. Cem Concr Compos 2000;22(6):445-52.

[63] Feng X, Garboczi EJ, Bentz DP, Stutzman PE, Mason TO. Estimation of the degree of hydration of blended cement pastes by a SEM point-counting procedure. Cem Concr Res 2004;34(10):1787-93.

[64] Pane I, Hansen W. Investigation of blended cement hydration by isothermal calorimetry and thermal analysis. Cem Concr Res 2005;35(6):1155-64.

[65] Hernández MG, Anaya JJ, Izquierdo MAG, Ullate LG. Application of micromechanics to the characterization of mortar by ultrasound. Ultrasonics 2002;40(1-8):217-21.

[66] Buil M, Revertegat E, Oliver J. A model of the attack of pure water or undersaturated lime solutions on cement. In: Gillian TM, Wiles CC, editors. Stabilization and solidification of hazardous, radioactive and mixed wastes. Philadelphia: American Society for Testing and Materials; 1992. p. 227-41.

[67] Hinsenveld M. A shrinking core model as a fundamental representation of leaching mechanisms in cement stabilized waste. Cincinnati: University of Cincinnati; 1992.

[68] Baker PG, Bishop PL. Prediction of metal leaching rates from solidified/ stabilized waster using the shrinking unreacted core leaching procedure. J Haz Mater 1997;52:311-33.

[69] Cui L, Cahyadi JH. Permeability and pore structure of OPC paste. Cem Concr Res 2001;31:277-82

[70] Castellote M, Andrade C. Modelling the carbonation of cementitious matrixes by means of the unreacted-core model, UR-CORE. Cem Concr Res 2008;38(12):1374-84

[71] Rozière E, Loukili A, Cussigh F. A performance based approach for durability of concrete exposed to carbonation. Constr Build Mater 2009;23:190-9.

[72] Papadakis VG, Vayenas CG, Fardis MN. Fundamental modelling and experimental investigation of concrete carbonation. $\mathrm{ACI}$ Mater J $1991 ; 88(4): 363-73$.

[73] Nguyen VH. Couplage degradation chimique - comportement en compression du beton. Paris: Ecole Nationale des Ponts et Chaussees; 2005.

[74] Perlot C. Influence de la decalcification de materiaux cimentaires sur les proprietes de transfert: application au stockage profond de dechets radioactifs. Toulouse: L'Universite Paul Sabatier de Toulouse; 2005. 
[75] Nguyen VH, Colina H, Torrenti JM, Boulay C, Nedjar B. Chemo-mechanical coupling behaviour of leached concrete. Part I: experimental results. Nucl Eng Des 2007;237(20-21):2083-9.

[76] Halim CE, Short SA, Scott JA, Amal R, Low G. Modelling the leaching of Pb, Cd, As, and $\mathrm{Cr}$ from cementitious waste using PHREEQC. J Haz Mater 2005;125(13):45-61.

[77] Qiao XC, Poon CS, Cheeseman CR. Transfer mechanisms of contaminants in cement-based stabilized/solidified wastes. J Haz Mater 2006;129(1-3):290-6.
[78] Idachaba MA, Nyavor K, Egiebor NO. Kinetic analysis of data obtained from studies on microbial degradation of cement waste forms, using shrinking core models. J Haz Mater 2003;99(1):57-69.

[79] Park K-B, Noguchi T, Plawsky J. Modeling of hydration reactions using neural networks to predict the average properties of cement paste. Cem Concr Res 2005;35(9):1676-84. 